US Army Corps

of Engineers ${ }_{\circledast}$

Engineer Research and

Development Center

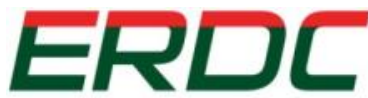

INNOVATIVE SOLUTIONS

for a safer, better world

Environmental Quality/Installations (EQ/I)

\title{
Development and Characterization of Small- Scale Washing Systems for Removal of Depleted Uranium Oxides
}

Ronald J. Unz, Jay P. McCown, Charles A. Waggoner, January 2018

Steven L. Larson, and John H. Ballard 
The U.S. Army Engineer Research and Development Center (ERDC) solves the nation's toughest engineering and environmental challenges. ERDC develops innovative solutions in civil and military engineering, geospatial sciences, water resources, and environmental sciences for the Army, the Department of Defense, civilian agencies, and our nation's public good. Find out more at www.erdc.usace.army.mil.

To search for other technical reports published by ERDC, visit the ERDC online library at http://acwc.sdp.sirsi.net/client/default. 


\section{Development and Characterization of Small- Scale Washing Systems for Removal of Depleted Uranium Oxides}

Ronald J. Unz, Jay P. McCown, and Charles M. Waggoner

Institute for Clean Energy Technology, Mississippi State University

205 Research Blvd.

Starkville, MS 39702

Steven L. Larson and John H. Ballard

Environmental Laboratory

U.S. Army Engineer Research and Development Center

3909 Halls Ferry Rd.

Vicksburg, MS 39180

Final Report

Approved for public release; distribution is unlimited.

Prepared for Headquarters, U.S. Army Corps of Engineers

Washington, DC 20314-1000

Under Department of Defense Appropriations Act Program Element 0603728A, "Depleted Uranium (DU) Clearance from DOD Ranges" 


\section{Abstract}

Researchers from the Mississippi State University Institute for Clean Energy Technology (MSU-ICET) and the U.S. Army Engineer Research and Development Center (ERDC) have identified procedures and methodologies for identifying leaching solutions to assist in the removal of depleted uranium (DU) oxides from contaminated soils. They developed a benchscale leach system to optimize leaching procedures and methodologies. This study identified that a 2 molar (M) acetic-acid solution with a 15\% (v/v) $0.3 \mathrm{M}$ hydroxylamine hydrochloride solution could remove approximately $70 \%$ of the uranium in the soil sample. Pretreating the soil with $3 \mathrm{M}$ hydrochloric acid improved leaching efficiency to approximately $90 \%$. The MSU-ICET research team developed the preliminary design of a mobile leaching system based on the hydrochloric-acid pretreatment followed by $2 \mathrm{M}$ acetic acid / 15\% (v/v) 0.3 M hydroxylamine hydrochloride leaching method. The trailer heap leach system is designed to be used on-site, eliminating the need for additional transport of radioactive, contaminated soils. This will reduce the risk of radioactive exposure for personnel and will eliminate potentially serious transportation accidents.

DISCLAIMER: The contents of this report are not to be used for advertising, publication, or promotional purposes. Citation of trade names does not constitute an official endorsement or approval of the use of such commercial products. All product names and trademarks cited are the property of their respective owners. The findings of this report are not to be construed as an official Department of the Army position unless so designated by other authorized documents. 


\section{Contents}
Abstract
.iv

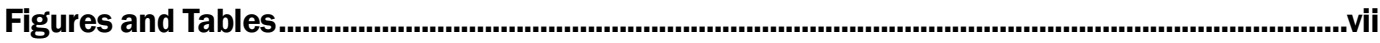

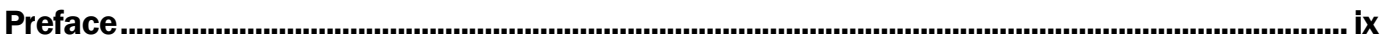
Acronyms and Abbreviations ............................................................................................................
Unit Conversion Factors ...................................................................................................................... xiii

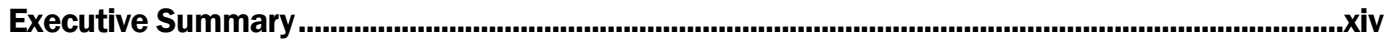
1 Introduction ................................................................................................................................ 1

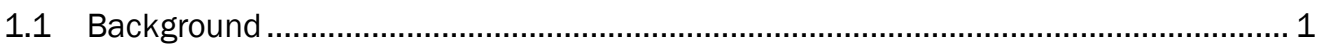

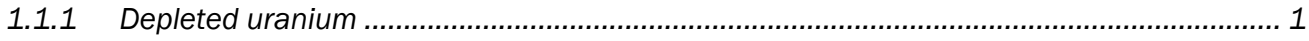

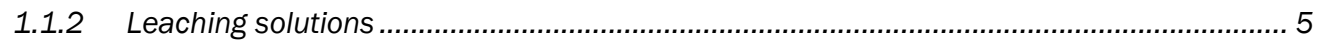

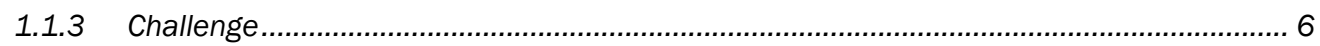

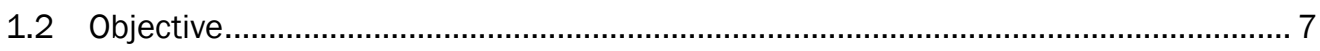

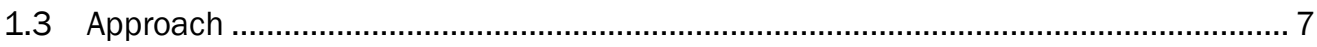

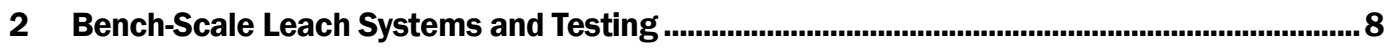

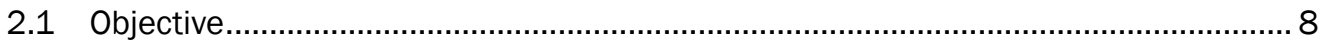

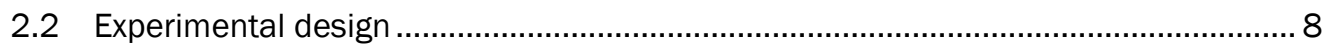

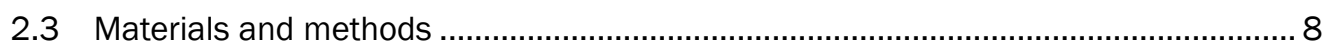

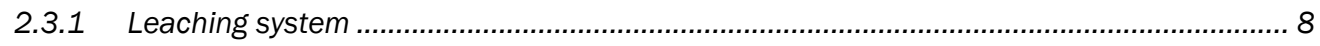

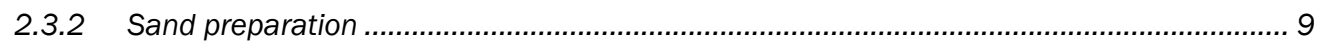

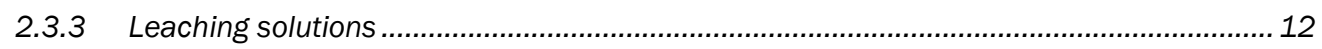

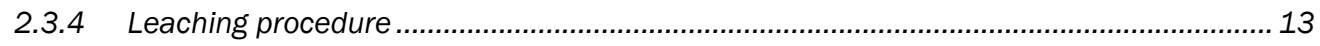

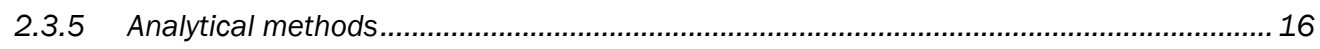

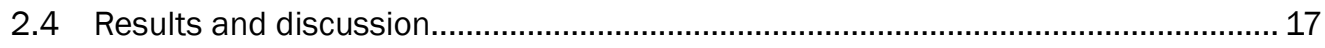

2.4.1 Leaching of uranium from U308-spiked sand ............................................................ 17

2.4.2 Leaching of uranium from sand: U3O8 versus U02 ….................................................. 18

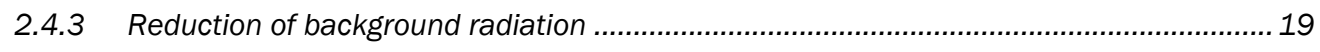

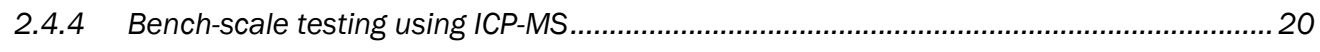

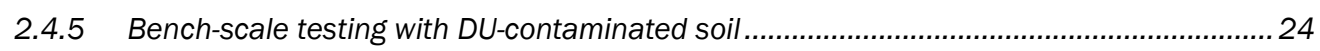

2.4.6 Hydrochloric-acid presoak leaching efficiency ..........................................................25

3 Optimization of Bench-Scale Chemical Leaching .................................................................29

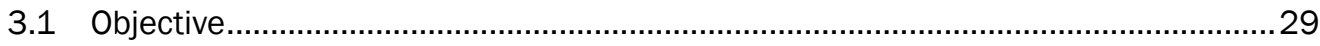

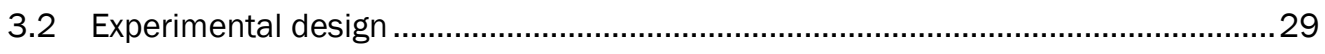

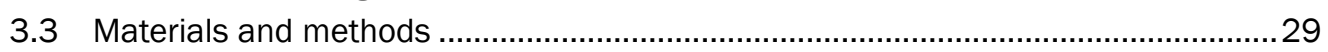

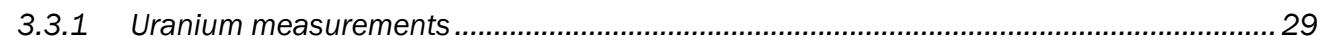

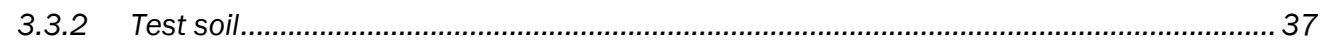

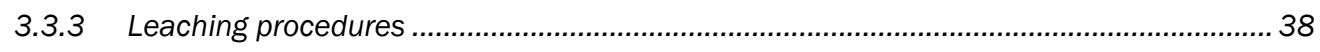

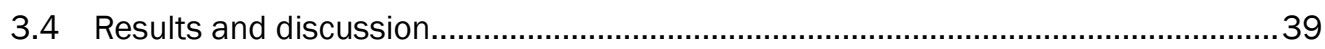




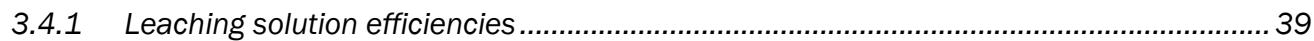

3.4.2 Comparison to Naturally Occurring Radioactive Materials (NORM)................................... 42

3.5 Conclusions and recommendations ............................................................ 43

4 Field-Ready Chemical Soil-Washing System ........................................................................44

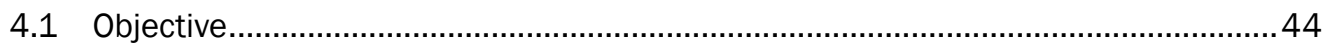

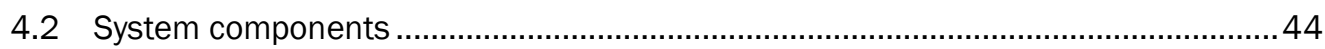

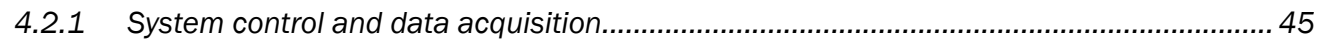

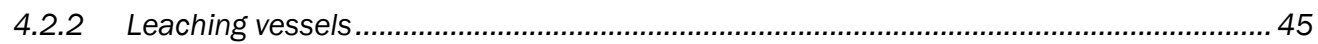

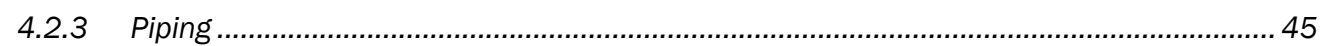

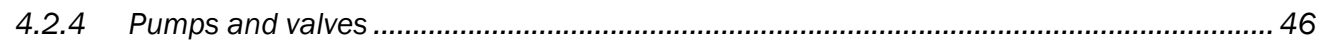

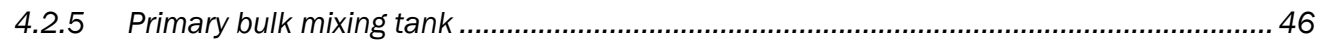

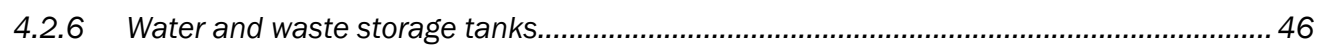

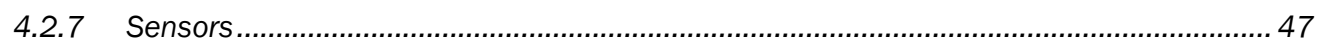

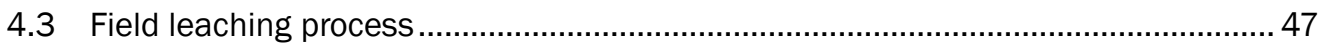

5 Conclusions...................................................................................................................................51

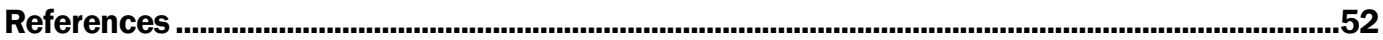

\section{Report Documentation Page}




\section{Figures and Tables}

\section{Figures}

1 Chart of the uranium decay series (U.S. Geological Survey, n.d.)......................................... 3

2 Decay scheme of U-235 (BateslsBack 2011) ....................................................................... 4

3 Experimental configuration with the mariotte bottle (left) and three soil columns

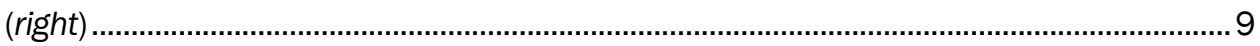

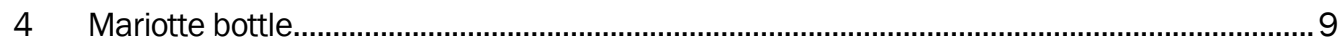

$5 \quad$ V-mixer used to mix soil samples ................................................................................1

6 Radioactive soil samples in the interior of one arm of the V-mixer ....................................11

7 Comparison of mass of uranium removed from soil through successive extractions with two different leaching solutions based on acetic acid .............................12

8 Pouring a DU-spiked soil sample into a soil column ..............................................................13

9 The leaching solution head on the soil column...............................................................14

10 Filling a leachate sample bottle...................................................................................14

11 Average leaching efficiencies of three concentrations of acetic acid / hydroxylamine hydrochloride on $\mathrm{U}_{3} \mathrm{O}_{8}$-spiked sand .......................................................17

12 Comparison of average leaching efficiencies of $1 \mathrm{M}$ acetic acid / 15\% 0.3 M hydroxylamine hydrochloride on either $\mathrm{U}_{3} \mathrm{O}_{8}$ - or $\mathrm{UO}_{2}$-spiked sand.....................................19

13 Lead shielding around the lanthanum bromide detector ..................................................19

14 Comparison of shielded background spectra (blue) to unshielded background

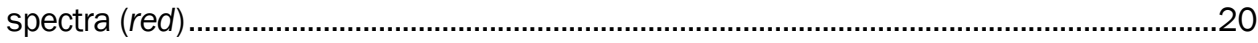

15 Leach efficiency for uranium-spiked sand and field-contaminated soil after

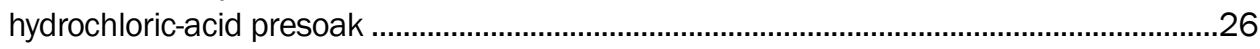

16 Results of extended leaching with hydrochloric-acid soaking of DU-contaminated

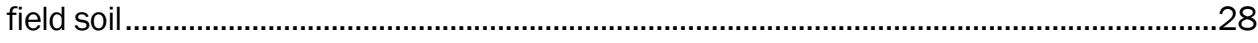

17 HPGe detector system used for analysis of uranium in soil samples ................................30

18 Screenshot depicting U-235 spectra in GammaVision with U-235 photopeaks

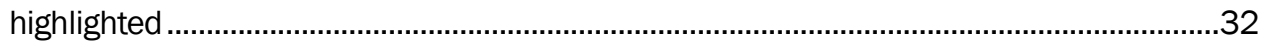

19 Example of a full-energy spectrum using an ORTEC GMX30 Detector and MatLab

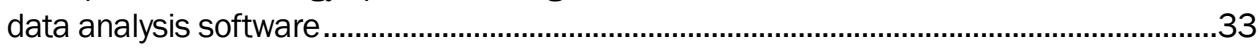

20 Example of a photopeak measured using an ORTEC GMX30 HPGe detector of the $185 \mathrm{keV}$ gamma ray emitted from U-235 ........................................................................34

21 Example of a photopeak measured using an ORTEC GMX30 HPGe detector for the 1001 keV gamma ray emitted from Pa-234m..............................................................34

22 Example of a full gamma-ray spectrum analysis report...................................................35

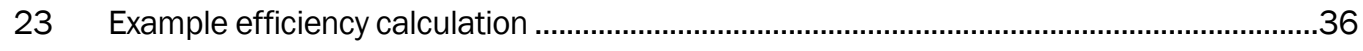

24 Shaker table used to agitate soil samples undergoing the leach procedure.......................39

25 Ratio of U-235 in DU-contaminated soil samples to background, control soil

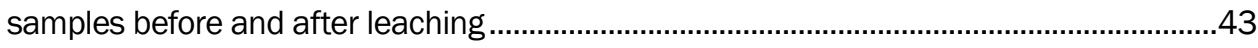

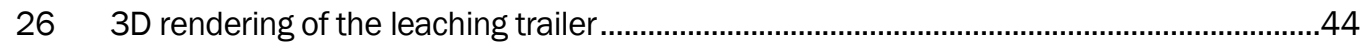

27 P\&ID diagram of batch mixing tanks, pumps, and sensors. Red arrows indicate the heap recirculation loop; blue arrows indicate the mixing loop.. 
28 P\&ID diagram of liquid transfer lines and leaching loops for the leaching system.

Red arrows indicate the heap recirculation loop 50

\section{Tables}

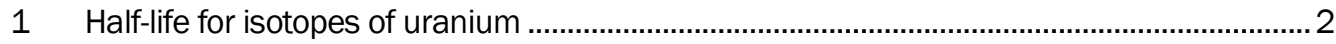

2 Gamma-ray emission probabilities for Pa-234m (Nichols et al. 2008) ................................. 3

3 Gamma-ray emission probabilities for U-235 ................................................................ 4

4 Review of uranium leaching solutions and procedures ……................................................ 5

5 Initial solutions used in bench-scale soil heap leach testing ............................................12

6 Calculated leaching efficiencies of $\mathrm{U}_{3} \mathrm{O}_{8}$ from sand using lanthanum bromide scintillation detectors .............................................................................................................

$7 \quad$ Results of the leaching procedure using $1 \mathrm{M}$ acetic-acid solution with $\mathrm{U}_{3} \mathrm{O}_{8}$ and

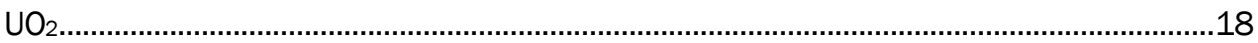

8 Test matrix of bench-scale soil leach testing of $\mathrm{UO}_{2}$ with uranium mass and leachate concentrations as test variables ........................................................................21

9 Uranium removal through heap leaching of $\mathrm{UO}_{2}$-contaminated soil based on ICP-

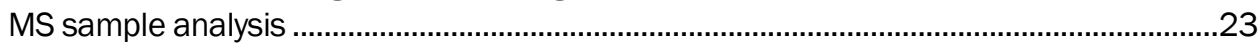

10 Efficiency of DU-contaminated soil leaching …...............................................................

11 Leaching efficiency of uranium from soil with an added hydrochloric-acid presoak

12 Comparison of the uranium removed (\%) in individual leaching steps following acid presoak times of varying duration for $\mathrm{U}_{3} \mathrm{O}_{8}$ - and $\mathrm{UO}_{2}$-spiked sand and $\mathrm{a}$ preleached DU-contaminated field soil

13 Results of extended leaching of DU-contaminated soil .......................................................28

14 Performance specifications for the HPGe detector used for detection of uranium

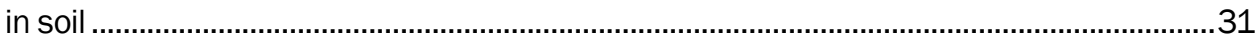

15 Channel number and gamma-ray energy used in automated software for U-235 .............34

16 Channel number and gamma-ray energy used in automated software for U-238 .............35

17 Experimental matrix of the second bench-scale leach test..................................................37

18 Calculated leaching efficiencies using the U-235 photopeak for each leach test and the U-238 photopeak for comparison

19 Calculated photopeak ratios between U-235 and U-238 pre- and postleaching.................41

20 Comparison of removal efficiency (\%) of uranium from DU-contaminated soil in a second set of leach tests using a $24 \mathrm{hr}$ hydrochloric-acid presoak and additional leaching with $3 \mathrm{M}$ acetic acid 


\section{Preface}

This report describes work conducted for the U.S. Army Engineer Research and Development Center (ERDC), Environmental Laboratory (EL), Environmental Quality/ Installations (EQ/I) Research Program, under “Depleted Uranium (DU) Clearance from DOD Ranges." The work was funded under the Department of Defense Appropriations Act Program Element 0603728A to develop innovative and cost-effective remediation solutions for sites contaminated with DU. Collaborative work was conducted by Mississippi State University via Cooperative Agreement W912HZ-16-20015 .

The work was performed by the Environmental Engineering Branch (CEERD-EPE) of the Environmental Processes and Engineering Division (CEERD-EP), U.S. Army Engineer Research and Development Center, Environmental Laboratory (ERDC-EL). At the time of publication, Dr. W. Andy Martin was Chief, CEERD-EPE; Mr. Warren Lorenz was Chief, CEERD-EP; and Dr. Elizabeth Ferguson was the Lead Technical Director for EQ/ I. The Deputy Director of ERDC-EL was Dr. J ack Davis, and the Director was Dr. Ilker Adiguzel.

Deborah Felt and Roy Wade (CEERD-EPE) provided in-house reviews for this report.

COL Bryan S. Green was the Commander of ERDC, and Dr. David Pittman was the Director. 


\section{Acronyms and Abbreviations}

\begin{tabular}{|c|c|}
\hline$\mu \mathrm{Ci}$ & Microcurie \\
\hline $\mathrm{AA}$ & Acetic Acid \\
\hline AEPI & Army Environmental Policy Institute \\
\hline ANOVA & Analysis of Variance \\
\hline $\mathrm{BD}$ & Bulk Density \\
\hline $\mathrm{Bi}$ & Bismuth \\
\hline BRAC & Base Realignment and Closure \\
\hline $\mathrm{C}_{6} \mathrm{H}_{8} \mathrm{O}_{7}$ & Citric Acid \\
\hline CERCLA & $\begin{array}{l}\text { Comprehensive Environmental Response, Compensation, and } \\
\text { Liability Act }\end{array}$ \\
\hline $\mathrm{CH}_{3} \mathrm{COOH}$ & Acetic Acid \\
\hline Co & Cobalt \\
\hline DOD & Department of Defense \\
\hline DU & Depleted Uranium \\
\hline DUS & Depleted Uranium Soil \\
\hline EL & Environmental Laboratory \\
\hline $\mathrm{EQ} / \mathrm{I}$ & Environmental Quality/ Installations \\
\hline ERDC & U.S. Army Engineer Research and Development Center \\
\hline FWFM & Full Width at Fiftieth of Maximum \\
\hline FWHM & Full Width Half Maximum \\
\hline FWTM & Full Width at Tenth of Maximum \\
\hline $\mathrm{H}_{2} \mathrm{O}_{2}$ & Hydrogen Peroxide \\
\hline $\mathrm{H}_{2} \mathrm{SO}_{4}$ & Sulfuric Acid \\
\hline
\end{tabular}




\begin{tabular}{|c|c|}
\hline HAN & Hydroxylamine Hydrochloride \\
\hline $\mathrm{HCl}$ & Hydrochloric acid \\
\hline $\mathrm{HNO}_{3}$ & Nitric Acid \\
\hline HPGe & High-Purity Germanium \\
\hline ICET & Institute for Clean Energy Technology \\
\hline ICP-MS & Inductively Coupled Plasma Mass Spectroscopy \\
\hline ID & Identification \\
\hline ISL & In Situ Leaching \\
\hline $\mathrm{keV}$ & Kiloelectronvolt \\
\hline $\mathrm{La}$ & Lanthanum \\
\hline M & Molar \\
\hline $\mathrm{MeV}$ & Megaelectronvolt \\
\hline $\mathrm{MnO}_{2}$ & Manganese Dioxide \\
\hline MSU & Mississippi State University \\
\hline $\mathrm{N} / \mathrm{A}$ & Not Applicable \\
\hline $\mathrm{Na}_{2} \mathrm{CO}_{3}$ & Sodium Carbonate \\
\hline $\mathrm{NaHCO}_{3}$ & Sodium Bicarbonate \\
\hline $\mathrm{NaI}$ & Sodium Iodide \\
\hline $\mathrm{NH}_{2} \mathrm{OH} \cdot \mathrm{HCL}$ & Hydroxylamine Hydrochloride \\
\hline NORM & Naturally Occurring Radioactive Materials \\
\hline $\mathrm{NU}$ & Natural Uranium \\
\hline P\&ID & Piping and Instrumentation Diagram \\
\hline $\mathrm{Pa}$ & Protactinium \\
\hline PD & Particle Density \\
\hline
\end{tabular}




$\begin{array}{ll}\text { PVC } & \text { Polyvinyl Chloride } \\ \text { Ra } & \text { Radon } \\ \text { RCRA } & \text { Resource Conservation and Recovery Act } \\ \text { SA } & \text { Specific Activity } \\ \text { SCADA } & \text { Supervisory Control and Data Acquisition } \\ \text { Th } & \text { Thorium } \\ \text { U } & \text { Uranium } \\ \mathrm{U}_{\text {US. EPA }} & \text { United States Environmental Protection Agency } \\ \mathrm{U}_{3} \mathrm{O}_{8} & \text { Triuranium Octoxide } \\ \mathrm{UO}_{2} & \text { Uranium Dioxide } \\ \text { V/v } & \text { Volume/ Volume } \\ \mathrm{VFD} & \text { Variable Frequency Drive }\end{array}$




\section{Unit Conversion Factors}

\begin{tabular}{|l|l|l|}
\hline Multiply & By & To Obtain \\
\hline cubic feet & 0.02831685 & cubic meters \\
\hline degrees Fahrenheit & $(\mathrm{F}-32) / 1.8$ & degrees Celsius \\
\hline feet & 0.3048 & meters \\
\hline gallons (U.S. liquid) & $3.785412 \mathrm{E}-03$ & cubic meters \\
\hline inches & 0.0254 & meters \\
\hline
\end{tabular}




\section{Executive Summary}

The U.S. Army has a history of managing and maintaining a large number of facilities that are used for developing and testing equipment and munitions. Some sites include ranges that may have been contaminated with depleted uranium (DU). Evaluating munitions and armor systems where DU is a primary component has been important to national security. It is critical that cost-effective and environmentally friendly technologies are developed for managing sites where DU weapon systems have resulted in the distribution of DU residues in soils.

Researchers from Mississippi State University and the U.S. Army Engineer Research and Development Center, Environmental Laboratory, have identified leaching solutions to assist in the removal of DU oxides from contaminated soils and the procedures to accomplish this in the field. They developed a bench-scale leach system to optimize leaching procedures and methodologies, and further investigations identified optimum methods for conducting leaches, calculating leaching efficiency, and addressing soil conditions where homogeneity may be a problem.

The laboratory investigation explored effective leaching solutions to remove uranium from soil that has been contaminated with DU. Solutions of acetic acid and hydroxylamine hydrochloride were evaluated at a variety of concentrations, temperatures, and leach duration. Researchers identified that a 2 molar (M) acetic-acid solution with a 15\% (volume/volume) $0.3 \mathrm{M}$ hydroxylamine hydrochloride solution was sufficient to remove approximately $70 \%$ of the uranium in the soil sample. Pretreating the soil with 3 $\mathrm{M}$ hydrochloric acid ( $\mathrm{HCl}$ ) improved leaching efficiency to approximately 90\%. Leaching solutions that are used in the ore processing industry (sulfuric and nitric acids) were also evaluated for comparative purposes.

Finally, this study included designing a mobile leaching system that can be used in the field to remediate DU-contaminated soils. The leaching system itself is attached to a large trailer that can be pulled behind a heavy-duty truck. The trailer is designed so that deployment is quick and easy, multiple leaching heaps can easily be used simultaneously, and leaching chemistry is monitored and adjusted dynamically. All leaching processes are controlled by a supervisory control and data acquisition system. Leaching performance is monitored by a variety of sensors and radiation detectors. 


\section{Introduction}

\subsection{Background}

\subsubsection{Depleted uranium}

Natural uranium (NU) is found in the environment in crustal rock and is composed of three primary isotopes of uranium (U): U-238, U-235, and U234 with percentages of $99.725 \%, 0.720 \%$, and $0.005 \%$, respectively (Richter et al. 1999). U-235 is fissile and is responsible for chain reactions inside nuclear reactors and nuclear weapons. However, the U-235 content in NU is insufficient to maintain a nuclear fission chain reaction. The NU must be refined to concentrate U- 235 for a nuclear fission chain reaction to be sustainable. The waste material from the enrichment process is called depleted uranium (DU). DU has a lower percentage of U-235 and U234 than NU (Army Environmental Policy Institute [AEPI] 1994), is defined as any $\mathrm{U}$ that has undergone the refining process, and has a range of U-235 concentration less than $0.7 \%$ (Nuclear Regulatory Commission 2015). The isotopic composition of DU used by the Department of Defense (DOD) is typically $99.8 \% \mathrm{U}-238,0.20 \% \mathrm{U}-235$, and $0.0001 \% \mathrm{U}-234$ (AEPI 1994).

DU has a large range of uses throughout a variety of industries. Industrial uses for DU include radiation shielding in hospitals, ballast on marine and aircraft, and counter weights (Betti 2003). DU has also been used by the U.S. Army to manufacture army-piercing munitions and tank armor systems. DU is an ideal metal for armor piercing due to its density, availability, pyrophoric properties, and self-sharpening characteristics. (AEPI 1994; Bleise et al. 2003).

All isotopes of $\mathrm{U}$ are radioactive, including those that make up NU and DU. NU has a specific activity (SA) of $0.7 \mu \mathrm{Ci} / \mathrm{g}$ (microcurie per gram ), and DU has an SA of $0.4 \mu \mathrm{Ci} / \mathrm{g}$. Extraction of U-235 and U-234 reduces the activity of DU because the half-lives of U-235 and U-234 are significantly shorter than U-238. Table 1 lists the half-life of each isotope discussed (U.S. Environmental Protection Agency [U.S. EPA] 2006; Nichols et al. 2008). 
Table 1. Half-life for isotopes of uranium.

\begin{tabular}{|l|c|}
\hline Isotope & Half-Life (Years) \\
\hline $\mathrm{U}-234$ & $2.455 \times 10^{5}$ \\
\hline $\mathrm{U}-235$ & $7.038 \times 10^{8}$ \\
\hline $\mathrm{U}-238$ & $4.468 \times 10^{9}$ \\
\hline
\end{tabular}

The decay schemes of the isotopes of interest for this research, U-235, U238 , and protactinium-234m (Pa-234m), are quite complicated. U-238 is the most abundant $U$ isotope in DU and does not readily emit x-rays or gamma rays. Both U-235 and U-238 form a decay chain. Pa- $234 \mathrm{~m}$ is an intermediate decay product of U-238. The U-238 chain is typically referred to as the "uranium series" (Figure 1), and the U-235 series chain is commonly called the "actinium series." The daughters of U-235 and U-238 are also radioactive. U-235 is a gamma emitter and can be detected directly; however, U-238 is not a gamma emitter and can be extremely difficult to detect using gamma-ray spectrometers. However, some of the U-238 daughter isotopes are gamma emitters and can be detected.

As seen in Figure 1, U alpha decays to thorium-234 (Th-234) 100\% of the time but will, on a very small percentage, decay to an excited state of Th234. The emission of gamma rays during this decay is too low to be actively observed in collected gamma-ray spectra. The half-life of Th-234 is approximately 24 days. In unperturbed samples, the activity of Th-234 is in secular equilibrium with U-238, a situation in which the quantity of a radioactive isotope remains constant because its production rate (e.g., due to decay of a parent isotope) is equal to its decay rate, which means that their activities are identical (U.S. EPA 2006).

The Th-234 undergoes beta-minus decay $100 \%$ of the time, and the nucleus will emit some gamma rays during the transition to the metastable state of Pa- $234 \mathrm{~m}$. All of the gamma rays emitted are at energies below $100 \mathrm{keV}$ (kiloelectronvolt).

The ORTEC GMX30 Gamma-X coaxial high-purity germanium (HPGe) detector used in these studies is most sensitive around of $100 \mathrm{keV}$. However, the $100 \mathrm{keV}$ region of the spectra typically shows interference with gamma rays and $\mathrm{x}$-rays from other naturally occurring isotopes within a soil sample. In samples with interference difficulties, the gamma rays from Th-234 are also typically unusable. However, the decay of Pa-234m does 
emit gamma rays at energies high enough to be used. The emission probabilities of $\mathrm{Pa}-234 \mathrm{~m}$ gamma rays (Table 2 ) are low, but their energies are high enough that they can be easily measured because other gamma rays in the data do not interfere (Nichols et al. 2008).

Figure 1. Chart of the uranium decay series (U.S. Geological Survey, n.d.).

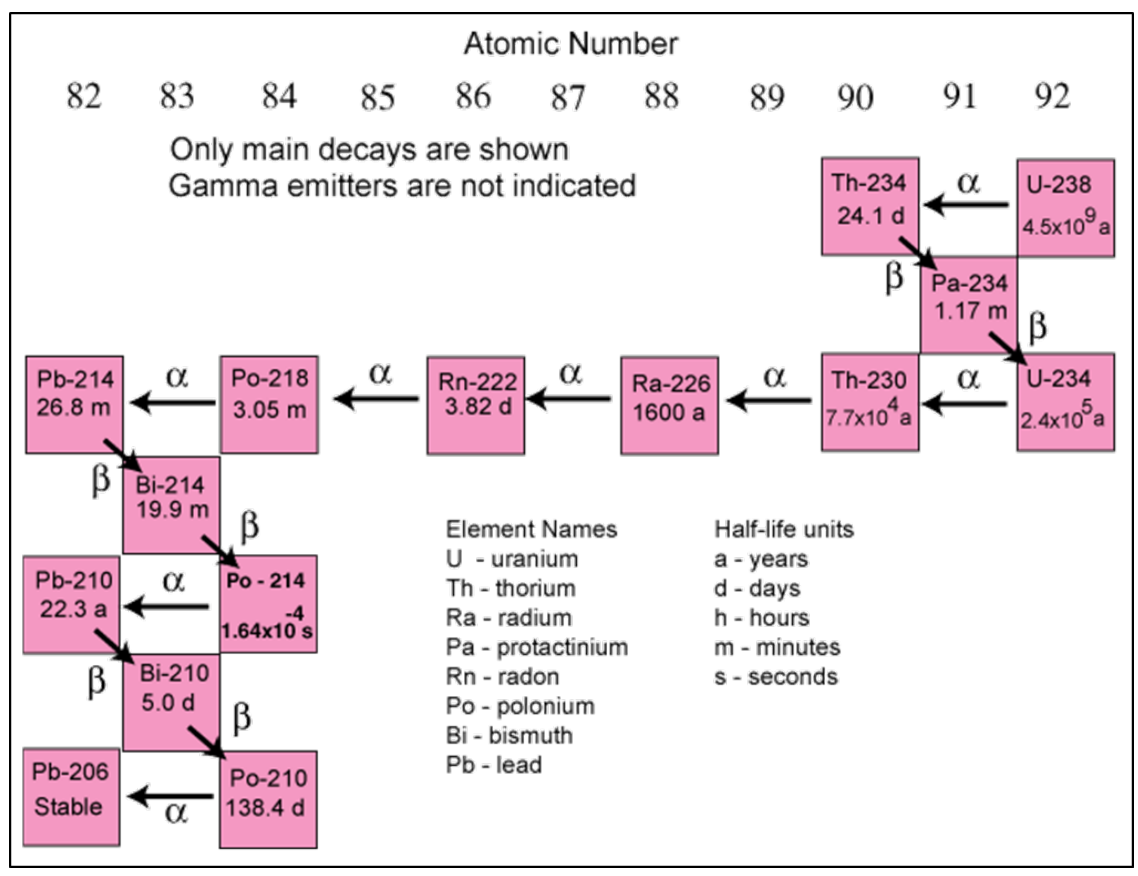

Table 2. Gamma-ray emission probabilities for $\mathrm{Pa}-234 \mathrm{~m}$

(Nichols et al. 2008).

\begin{tabular}{|c|c|}
\hline Energy (keV) & Emission Probability (\% decay) \\
\hline 258.2 & 0.07 \\
\hline 742.8 & 0.096 \\
\hline 766.4 & 0.318 \\
\hline 786.3 & 0.054 \\
\hline 1001.0 & 0.832 \\
\hline
\end{tabular}

The $1001 \mathrm{keV}$ gamma from $\mathrm{Pa}-234 \mathrm{~m}$ is prominent in spectra from soil samples containing DU or NU. Literature has shown the $1001 \mathrm{keV}$ photopeak of Pa-234m to be a reliable method for measuring $\mathrm{U}$ in samples (Yücel et al. 1998). However, the use of Pa-234m is heavily dependent on the secular equilibrium being maintained with Th-234 and on the secular equilibrium between Th-234 and U-238 also being maintained. Secular equilibrium is reached in approximately 240 days or 10 times the Th-234 half-life. 
U-235 alpha decays and has multiple gamma-ray emissions that have high emission probabilities. U-235 also has energies above $100 \mathrm{keV}$, and the energies do not interfere with the energies of other isotopes. Table 3 provides a list of gamma-ray energies and emission probabilities for U-235, and Figure 2 shows the decay scheme.

Table 3. Gamma-ray emission probabilities for U-235.

\begin{tabular}{|c|c|}
\hline Energy (keV) & Emission Probability (\% decay) \\
\hline 109.2 & 1.54 \\
\hline 140.8 & 0.22 \\
\hline 143.8 & 10.96 \\
\hline 163.3 & 5.08 \\
\hline 182.6 & 0.34 \\
\hline 185.7 & 57.2 \\
\hline 194.9 & 0.63 \\
\hline 202.1 & 5.01 \\
\hline 221.38 & 0.12 \\
\hline
\end{tabular}

Figure 2. Decay scheme of U-235 (BateslsBack 2011).

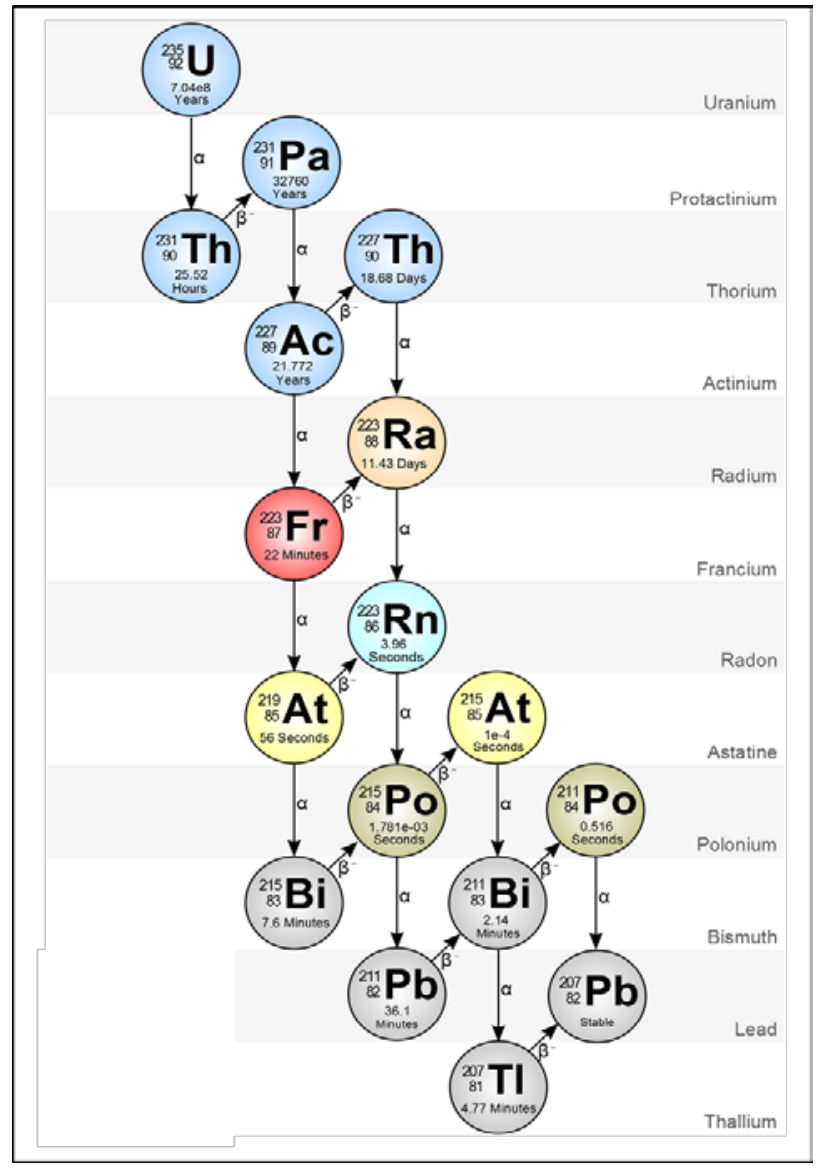




\subsubsection{Leaching solutions}

A range of leaching solutions for DU have been used in industry and in other remediation studies. Acid and alkaline solutions have been used in ore processing and In Situ Leaching (ISL) techniques. The primary solutions of use are sodium bicarbonate, sodium carbonate, nitric acid, citric acid, and sulfuric acid; the last three are used in the standard leaching process. However, sulfuric acid is typically chosen for its availability and low cost and because it is more environmentally friendly than other acids (Edwards and Oliver 2000). Sodium carbonate and sodium bicarbonate solutions are typically used with ores with high carbonate concentrations (Seidel 1981; International Atomic Energy Association 1993). Table 4 lists the solutions used in previous studies and their relative efficiency of $U$ removal.

Table 4. Review of uranium leaching solutions and procedures.

\begin{tabular}{|c|c|c|c|c|c|}
\hline Solution & Concentration & $\begin{array}{l}\text { Leach } \\
\text { Duration }\end{array}$ & Additives & $\begin{array}{l}\text { Efficiency } \\
(\%)\end{array}$ & References \\
\hline \multirow{5}{*}{$\begin{array}{l}\text { Sodium } \\
\text { Bicarbonate } \\
\left(\mathrm{NaHCO}_{3}\right)\end{array}$} & $0.1 \mathrm{M}^{*}$ & 6 days & None & $<30$ & Choy et al. (2006) \\
\hline & $0.1 \mathrm{M}$ & $\mathrm{N} / \mathrm{A}^{\dagger}$ & None & $20-94$ & Phillips et al. (1995) \\
\hline & $0.5 \mathrm{M}$ & 6 days & None & $50-60$ & Choy et al. (2006) \\
\hline & $0.5 \mathrm{M}$ & 2 days & None & 52 & Duff et al. (1998) \\
\hline & $0.1 \mathrm{M}$ & $\mathrm{N} / \mathrm{A}$ & Hydrogen Peroxide & $80-90$ & Choy et al. (2006) \\
\hline \multirow[t]{2}{*}{$\begin{array}{l}\mathrm{NaHCO}_{3} \text { and } \\
\text { Sodium } \\
\text { Carbonate } \\
\left(\mathrm{Na}_{2} \mathrm{CO}_{3}\right)\end{array}$} & $\begin{array}{c}0.1 \mathrm{M} \mathrm{CO}_{3}{ }^{2} \\
1: 1 \text { ratio of } \\
\text { Bicarbonate to } \\
\text { Carbonate }\end{array}$ & 4 days & None & $70-80$ & Mason et al. (1997) \\
\hline & $\begin{array}{c}0.12 \mathrm{M} \mathrm{CO}_{3} \\
1: 1 \text { Ratio of } \\
\text { Bicarbonate to } \\
\text { Carbonate }\end{array}$ & 7 days & $\begin{array}{c}\text { Manganese } \\
\text { Dioxide }\left(\mathrm{MnO}_{2}\right)\end{array}$ & $30-42$ & Frackiewicz et al. (2012) \\
\hline Nitric Acid $\left(\mathrm{HNO}_{3}\right)$ & $1.0 \mathrm{M}$ & $4 \mathrm{hr}$ & None & $84-100$ & Phillips et al. (1995) \\
\hline \multirow{2}{*}{$\begin{array}{l}\text { Citric Acid } \\
\left(\mathrm{C}_{6} \mathrm{H}_{8} \mathrm{O}_{7}\right)\end{array}$} & $0.2 \mathrm{M}$ & 6 days & None & $30-60$ & Choy et al. (2006) \\
\hline & $0.2-0.4 \mathrm{M}$ & 3 days & None & $60-50$ & Francis and Dodge (1998) \\
\hline \multirow{3}{*}{$\begin{array}{l}\text { Sulfuric Acid } \\
\left(\mathrm{H}_{2} \mathrm{SO}_{4}\right)\end{array}$} & $1 \mathrm{M}$ & 2 days & None & 44 & Duff et al. (1998) \\
\hline & $1 \mathrm{M}$ & 8 days & $\mathrm{MnO}_{2}$ & $51-55$ & Frackiewicz et al. (2012) \\
\hline & $1 \mathrm{M}$ & $6 \mathrm{hr}$ & None & 75 & Guettaf et al. (2009) \\
\hline \multirow{2}{*}{$\begin{array}{l}\text { Acetic Acid } \\
\left(\mathrm{CH}_{3} \mathrm{COOH}\right)\end{array}$} & $25 \%$ & $15 \min$ & None & $60-70$ & S. Larson (pers. comm.) \\
\hline & $25 \%$ & $15 \mathrm{~min}$ & $\begin{array}{l}\text { Hydroxylamine } \\
\text { hydrochloride } \\
\left(\mathrm{NH}_{2} \mathrm{OH} \cdot \mathrm{HCL}\right)\end{array}$ & 74 & S. Larson (pers. comm.) \\
\hline
\end{tabular}

* Molar

† Not applicable 


\subsubsection{Challenge}

Depleted uranium kinetic penetrators have been fired at a variety of testing locations and in battle. Firing DU-containing munitions results in impact areas with residual DU. Because of their pyrophoric and self-sharpening characteristics, DU penetrators may also produce U aerosols when they impact a surface, which quickly oxidize and typically produce a mixture of uranium dioxide $\left(\mathrm{UO}_{2}\right)$ and triuranium octoxide $\left(\mathrm{U}_{3} \mathrm{O}_{8}\right)$ (Salbu et al. 2003; Crean 2013). Aerosolized DU can then settle on the ground or surfaces at the impaction site and can also travel downwind. While aerosols typically do not travel beyond $100 \mathrm{~m}$, they are still a potential hazard further downwind (Bleise at al. 2003). Metallic DU in soil corrodes over time, producing metals such as shoepite and metashoepite. These soluble forms of $U$ may result in U mobility in the environment (Buck et al. 2004; Mellini and Riccobono 2005; Toque et al. 2014). Corroded penetrators are also a risk to groundwater as the solubility of U oxides could be high enough to result in mobile U in soil (AEPI 1994; Bleise et al. 2003).

Any Army-supervised DU testing facilities undergoing closure must be remediated of DU contamination to standards developed under the Comprehensive Environmental Response, Compensation, and Liability Act (CERCLA) and the Resource Conservation and Recovery Act (RCRA) before the testing areas can be released for unrestricted use under the Base Realignment and Closure (BRAC) program (U.S. EPA 2006). In addition, sites contaminated with DU must meet the Nuclear Regulatory Commission and Department of Energy regulations (U.S. EPA 2006).

The primary costs of remediating a site contaminated with DU are excavation, transport, and disposal of the contaminated soils. Locating and separating contaminated soil from uncontaminated soil on-site should reduce these costs. The Mississippi State University Institute for Clean Energy Technology (MSU-ICET) developed survey systems that have been used to identify contamination sites with high precision (Unz et al. 2011; Vaughn et al. 2011). Accurate discrimination tools are required to avoid excavating, and then treating, clean soils along with the DU-contaminated soils. Contaminated soils can be mechanically separated to remove large pieces of zero-valent DU and attached oxides. Chemical extraction techniques can then be used to leach $\mathrm{U}$ oxides from contaminated soil fines (Larson et al. 
2009, 2012; McCown et al. 2015). This can also potentially reduce costs of remediation (Walters et al. 2014).

\subsection{Objective}

The primary objective of this research was to establish the optimal leaching solution for performing the chemical separation of DU from contaminated soils. The secondary objective was to use information gathered from bench-scale leach testing to design a field-deployable leaching system for larger scale, on-site soil remediation.

\subsection{Approach}

This study used bench-scale leach testing to estimate the efficiency of leach heaps and chemical leaching solutions and developed laboratory infrastructure to perform the leaching experiments. For example, a large glove box was constructed to contain the bench-scale testing.

Soil samples underwent chemical leaching processes in a variety of configurations and using different procedures. Soil samples were analyzed for their U content before and after leaching to identify the overall leaching efficiency. The methods used for identifying leaching performance included gamma detectors (lanthanum bromide and high-purity germanium) and inductively coupled plasma mass spectrometry (ICP-MS). ICP-MS samples were analyzed at the U.S. Army Engineer Research and Development Center (ERDC).

This report discusses infrastructure developed, testing methodologies, and results. Information and experience gained during laboratory bench-scale testing (McCown et al. 2015) coupled with work conducted during previous MSU-ICET efforts (Larson et al. 2009, 2012) were used to design a soil-leaching trailer for large-scale, on-site, evaluation of leaching processes. 


\section{Bench-Scale Leach Systems and Testing}

\subsection{Objective}

The primary objective of the bench-scale testing was to leach DU-contaminated soils with various leachants and to calculate leaching efficiencies in a controlled manner.

\subsection{Experimental design}

Sand spiked with $\mathrm{U}$ oxides $\left(\mathrm{UO}_{2}\right.$ or $\mathrm{U}_{3} \mathrm{O}_{8}$ ) was placed into a bench-scale column leach system. Leaching solutions were allowed to percolate through the test soil columns for a set amount of time. Leaching efficiency was calculated from pre- and postleach U concentrations in the soils.

\subsection{Materials and methods}

\subsubsection{Leaching system}

The bench-scale soil-leaching system had three primary components: soil columns, a mariotte-type bottle, and a pump (Figure 3). The columns were constructed of 2 in. clear polyvinyl chloride (PVC) tubes with end caps on the bottom. Ball valves were placed near the top of the column and on the bottom. The top ball valve was used for the introduction of leaching solution to the column, and the bottom ball valve was used to control the flow rate of the leaching solution passing through and leaving the soil column. Each soil column had glass wool at the bottom of the column. The soil samples sat on top of the glass wool, which acted as filter media retaining the soil sample while the leachate exited the column.

The purpose of the mariotte bottle (Figure 4) was to create a constant head pressure in the soil columns. The mariotte bottle was constructed of 6 in. and 1 in. PVC pipes and was composed of two separate chambers. The top chamber was fitted with a tube in the middle that drained to the bottom chamber. A diastolic pump pumped leaching solution from the bottom chamber to the top chamber. Once the top chamber was filled, any additional solution above the draining tube drained back down to the lower chamber. This resulted in a constant level of leaching solution in the upper chamber. The top chamber was then attached to the soil columns. Liquid from the mariotte bottle and the head in the soil columns was always at 
the same level. The mariotte bottle was also used to store leaching solution that could be added manually to each column as needed.

Figure 3. Experimental configuration with the mariotte bottle (left) and three soil columns (right).

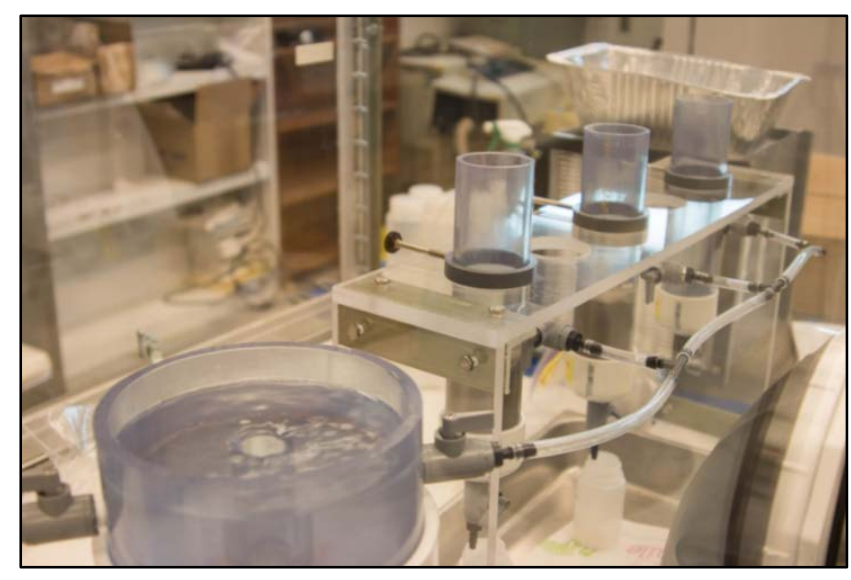

Figure 4. Mariotte bottle.

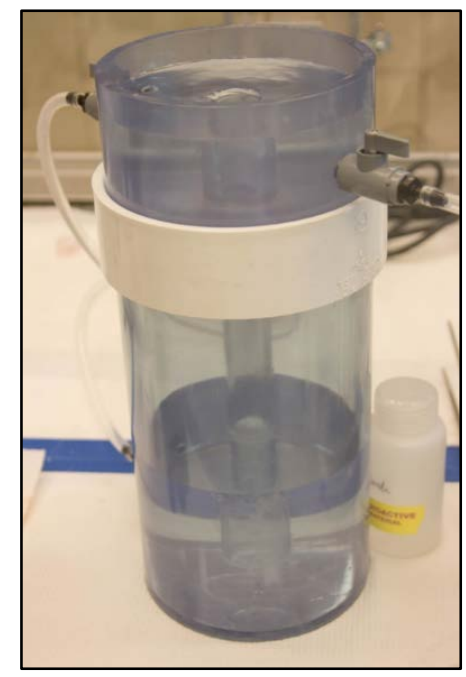

\subsubsection{Sand preparation}

The first nine soil samples were constructed using playground sand and $\mathrm{U}_{3} \mathrm{O} 8$. The bulk density for the sand was found to be $1.473 \mathrm{~g} / \mathrm{ml}$; therefore, $294.7 \mathrm{~g}$ of sand were required to achieve $200 \mathrm{ml}$ of sand in each sample.

The pore volume of the sand was calculated using Equation (1), with BD being the bulk density and PD being the particle density: 


$$
P=1-\frac{B D}{P D}
$$

The particle density for quartz is $2.65 \mathrm{~g} / \mathrm{cm}^{3}$. The porosity was calculated using data from the bulk density measurements, and it was found that the playground sand used in these experiments had a porosity of $44.4 \%$. Testing procedures called for six times the pore volume of leaching solution to be used. With the measured porosity, the pore volume was calculated to be $88.9 \mathrm{ml}$.

Each sample was made in a $250 \mathrm{ml}$ Nalgene bottle, which was initially filled with $294.7 \mathrm{~g}$ of sand. An analytical balance with a resolution of $0.1 \mathrm{mg}$ was used for measuring out the mass of $\mathrm{U}_{3} \mathrm{O}_{8}$ required for each sample. Triuranium octoxide is $95.43 \% \mathrm{U}$ by mass. For $200 \mathrm{ml}$ of soil in each sample, $0.2096 \mathrm{~g}$ of $\mathrm{U}_{3} \mathrm{O}_{8}$ is required to achieve $1 \mathrm{~g} / \mathrm{L}$ of $\mathrm{U}$ concentration.

The $\mathrm{U}_{3} \mathrm{O}_{8}$ material was made using $\mathrm{DU}$. Specific activity was calculated according to Equation (2) with the assumption that the isotopic concentration for DU is $99.7994 \% \mathrm{U}-238,0.2 \% \mathrm{U}-235$, and $0.0006 \% \mathrm{U}-234$. In this case, the SA for U-238 and U-235 is calculated as

$$
S A_{i}=3.7 \times 10^{7} \frac{A_{R a} T_{R a}}{A_{i} T_{i}} \frac{B q}{g}
$$

where $A_{R a}$ and $T_{R a}$ are the atomic weight and half-life of radon-226 (Ra226), respectively.

When $A_{i}$ and $T_{i}$ are the atomic weight and half-life of the isotope of interest, U-238, for example becomes

$$
S A_{238_{U}}=15,582 \frac{B q}{g} .
$$

And the SAs for U-235 and U-234 are

$$
\begin{gathered}
S A_{235_{U}}=80,870 \frac{B q}{g} \\
S A_{234_{U}}=2.328 \times 10^{8} \frac{B q}{g} .
\end{gathered}
$$


From the above calculations, the total SA of DU is

$$
S A_{D U}=17,110 \frac{B q}{g} .
$$

Samples constructed of sand and doped with $\mathrm{U}$ oxides were placed in a vmixer (Figure 5). Sample bottles were wrapped in foam and placed in one of the arms of the mixer (Figure 6). Radioactive samples were tumbled in one arm of the mixer for a specified time.

Figure 5. V-mixer used to mix soil samples.

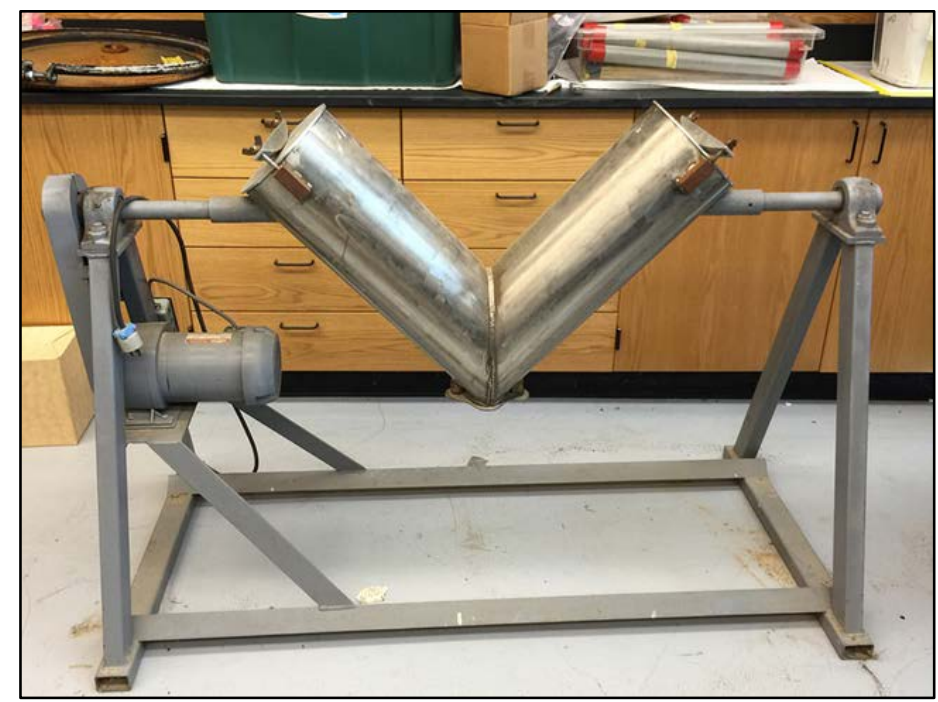

Figure 6. Radioactive soil samples in the interior of one arm of the V-mixer.

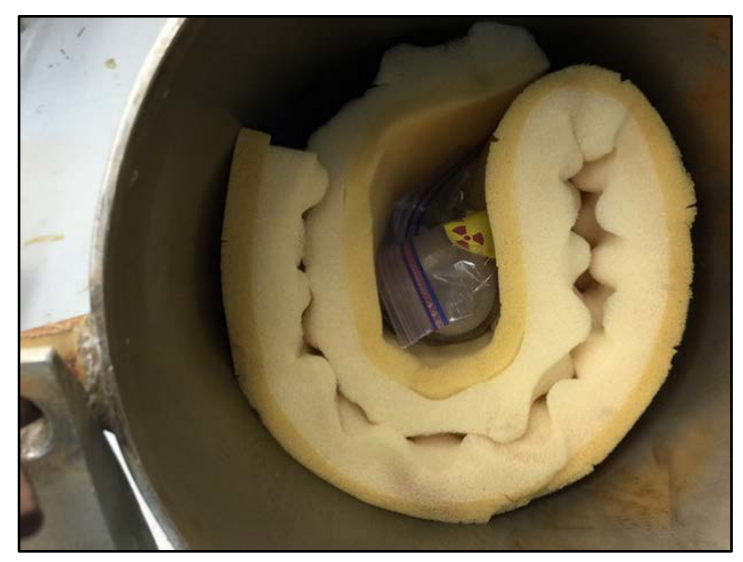




\subsubsection{Leaching solutions}

The primary leaching solutions used in the bench-scale leaching study were variations on acetic acid (AA) plus hydroxylamine (HAN) hydrochloride. Selection of these solutions was based on the results of preliminary research conducted at the ERDC Environmental Laboratory (S. Larson, pers. comm., May 2015). Leaching was accomplished through several soil rinses with the test solution, each rinse requiring approximately $15 \mathrm{~min}$ contact time at room temperature. As seen in Figure 7, in preliminary testing, $62 \%$ and $74 \%$ of the initial mass of $U$ in the soil sample were removed by AA and AA with HAN, respectively. Table 5 describes the experimental design to optimize the extractive ability of these solutions.

Figure 7. Comparison of mass of uranium removed from soil through successive extractions with two different leaching solutions based on acetic acid.

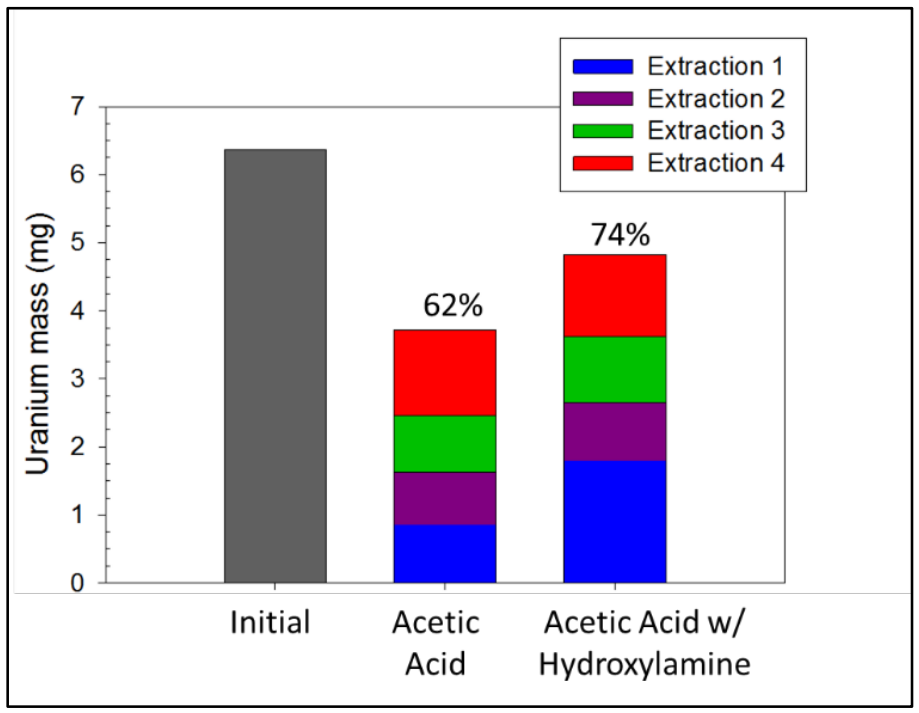

Table 5. Initial solutions used in bench-scale soil heap leach testing.

\begin{tabular}{|l|c|c|}
\hline \multicolumn{1}{|c|}{ Test Solution } & $\begin{array}{c}\text { Acetic-Acid } \\
\text { Concentration }\end{array}$ & $\begin{array}{c}\text { Percentage of 0.3 M } \\
\text { Hydroxylamine } \\
\text { Hydrochloride (v/v) }\end{array}$ \\
\hline Solution 1 & $1 \mathrm{M}$ & $15 \%$ \\
\hline Solution 2 & $2 \mathrm{M}$ & $15 \%$ \\
\hline Solution 3 & $3 \mathrm{M}$ & $15 \%$ \\
\hline
\end{tabular}

* Volume/volume 


\subsubsection{Leaching procedure}

Three soil columns were used to test three separate soil samples with an identical leaching solution. Soil samples were carefully poured into columns (Figure 8) when beginning the leaching procedure. The surface of the soil columns was smoothed using a stainless steel spatula. A gentle shake of the columns further leveled the surface.

Figure 8. Pouring a DU-spiked soil sample into a soil column.

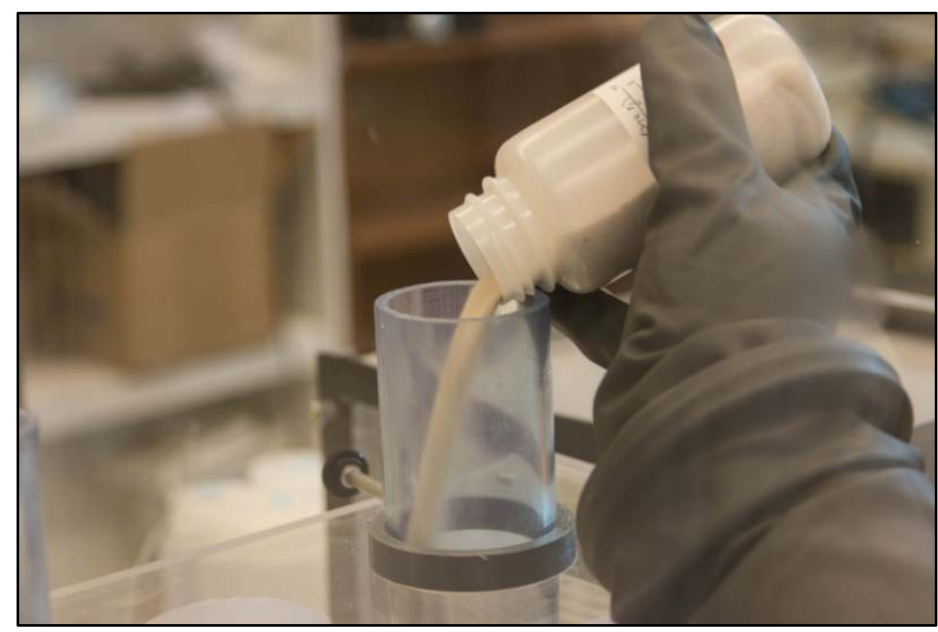

Leaching solution was slowly added to each column by opening the ball valves on the mariotte bottle and upper end of the soil columns. Leaching solution was allowed to flow into each column until the level of the leaching solution reached the bottom of the ball valve and no more air bubbled to the surface of the column (Figure 9). At this point, the upper ball valves on the soil columns were closed.

A ball valve, fitted with a barbed fitting, was located under each column (Figure 10). Premarked $125 \mathrm{ml}$ bottles were used to collect pore-volume samples. The bottles were placed under the ball-valve barbed fitting. Each lower ball valve was slowly opened until the leachate began to flow out. The flow rate of the column was adjusted to a rate of 1- 2 drops per second. Each bottle was marked with a line at the $89 \mathrm{ml}$ mark to indicate one pore volume and was labeled with a unique identification (ID) for each of the pore volumes. 
Figure 9. The leaching solution head on the soil column.

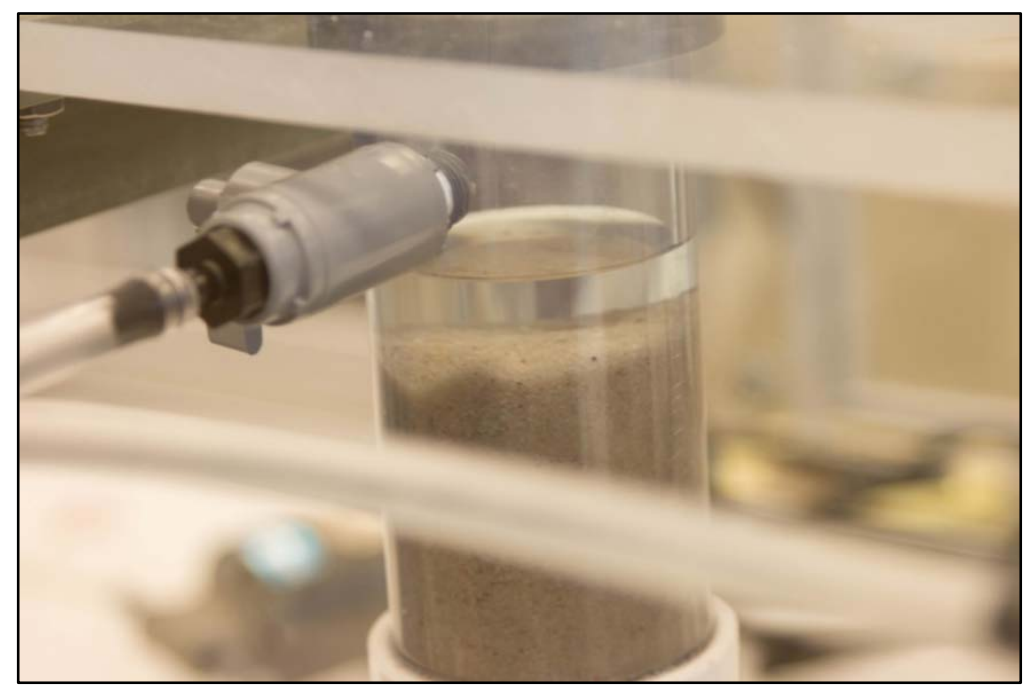

Figure 10. Filling a leachate sample bottle.

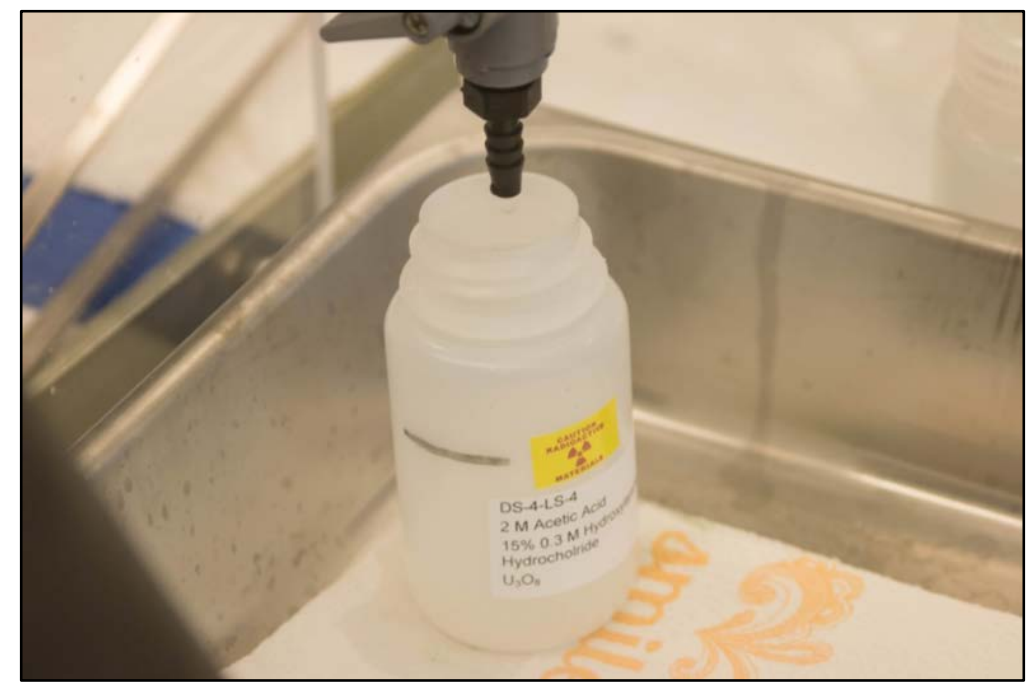

The head of the leaching solution fell as the solutions passed through the columns. Each head was manually maintained at a height of 2 to $2.5 \mathrm{~cm}$ by opening the upper ball valves on the columns until the height of the solution reached the appropriate level.

Each leachate sample bottle was replaced when the pore-volume level was reached. The head level on the sixth and final pore-volume samples was allowed to run low during the final leaching step without being topped off.

Each soil column was drained of any remaining solution at the end of leaching and was removed from the column holder. A weighing boat was 
placed on top of each column, and the column was inverted to allow the sample to fall into the weighing boat. Long tweezers were used to pull the glass wool from the bottom of the column. The wool was used to work additional material from the interior of the column into the weighing boat.

The wet soil samples were then placed onto a stainless steel pan and heated to dryness for $24 \mathrm{hr}$ at $49^{\circ} \mathrm{C}$ to $54^{\circ} \mathrm{C}$. The columns remained in the glove box over night to dry. The samples were removed from the oven after $24 \mathrm{hr}$ and allowed to cool for approximately an hour before being returned to their original bottles. Any remaining sand in the dry soil columns was transferred to the appropriate bottle by gently tipping the column upside down and tapping the side of the column. The glass wool was placed inside the top of the bottle in case any $\mathrm{U}$ was left behind on the wool.

Details of the leaching procedure for testing using the bench-scale leach system is as follows:

1. Soil samples were placed on top of a lanthanum bromide detector, and a spectrum was collected for $6 \mathrm{hr}$. The total counts from the spectrum were used for the initial counts for the soil sample.

2. Test soil was carefully added to the soil column and leveled.

3. The valve at the top of the column was used to slowly add leaching solution to minimize disturbing the soil bed.

4. The upper valve on the soil volume was closed when the proper head of the leaching solution was reached.

5. The column was tapped repeatedly to remove any air bubbles within the soil columns and was left to sit for $5 \mathrm{~min}$ to completely wet the soil bed.

6. A premarked Nalgene bottle was placed under the soil column to catch the leachate.

7. The bottom valves were opened slowly to achieve a flow-rate of roughly 12 drops per second. This flow rate would generate approximately one pore volume of leachate every 15- $20 \mathrm{~min}$.

8. The head of the leaching solution was adjusted and maintained manually by using the valve at the top of each soil column, maintaining a head of 2 to $2.5 \mathrm{~cm}$.

9. New bottles were placed at the bottom of each soil column once the first leachate bottles were filled with one pore volume of leachate. This process was repeated six times. 
10. No more leaching solution was added to the soil column when the sixth leachate bottle was placed under the soil column.

11. Final leachate bottles were used to drain the remainingleachate from the soil columns.

12. Soil samples were removed from the soil column and dried in an oven at $49^{\circ} \mathrm{C}$ to $54^{\circ} \mathrm{C}$ for $24 \mathrm{hr}$.

13. The soil dried into firm masses. These masses were broken up, and the soil was reintroduced into their original bottles.

14. Dried soil in the columns was easily tapped loose and poured into the bottles with the dried oolumn soil.

15. Soil spectra were collected using lanthanum bromide for postleaching measurements.

16. The leaching efficiency of the sample was calculated.

\subsubsection{Analytical methods}

Leached soil samples were analyzed on a $3 \times 3$ lanthanum bromide scintillation detector fitted with an ORTEC DigiBase to estimate the efficiency of the leaching solution. For efficiency calculations, total counts measured from the spectra were compared before and after the samples went through the leaching process. The detector was calibrated identically each day prior to being used due to the potential of spectral drift of scintillation detectors.

Measured sample spectra were corrected for background radiation. Equation (3) was used to estimate the efficiency of the samples. Gamma-ray emissions from the sample without any U oxides present (sand only) were also measured along with background spectra. All soils, including sand, are radioactive to some extent. The sand measurements identified any radiation being emitted from the sand itself. The calculation is shown in Equation (3), where $\mathrm{C}=$ counts:

$$
\text { Efficiency }=\left(1-\frac{C_{\text {Pre,Sample }}-C_{\text {Sand }}}{C_{\text {post }, \text { sample }}-C_{\text {sand }}}\right)
$$

where

$$
\begin{aligned}
C_{\text {Pre,Sample }} & =C_{\text {Pre,Sample,Total }}-C_{\text {Background }} \\
C_{\text {Sand }} & =C_{\text {Sand,Total }}-C_{\text {Background }} \\
C_{\text {Post,Sample }} & =C_{\text {Post,Sample,Total }}-C_{\text {Background }} .
\end{aligned}
$$




\subsection{Results and discussion}

\subsubsection{Leaching of uranium from U308-spiked sand}

This study ran nine spiked-sand leaching-column evaluations using the bench-scale leaching procedure. Table 6 and Figure 11 provide the replicate number, leaching solution composition, and the initial results.

Table 6. Calculated leaching efficiencies of $\mathrm{U}_{3} \mathrm{O}_{8}$ from sand using lanthanum bromide scintillation detectors.

\begin{tabular}{|c|c|c|c|c|c|}
\hline $\begin{array}{l}\text { DU Sample } \\
\qquad\left(\mathrm{U}_{3} \mathrm{O}_{8}\right)\end{array}$ & $\begin{array}{l}\text { Acetic-Acid } \\
\text { Concentration } \\
\text { (M) }\end{array}$ & $\begin{array}{l}\text { Percentage of } \\
\text { Hydroxylamine } \\
\text { Hydrochloride } \\
\text { (\%) }\end{array}$ & $\begin{array}{l}\text { Leaching } \\
\text { Duration } \\
\text { (min) }\end{array}$ & $\begin{array}{l}\text { Leaching } \\
\text { Efficiency } \\
\text { (\%) }\end{array}$ & $\begin{array}{l}\text { Avg. of Leaching } \\
\text { Efficiency } \\
\text { (\%) }\end{array}$ \\
\hline $\operatorname{Rep} 1$ & 1 & 15 & 85 & 18 & \multirow[t]{3}{*}{$18.67 \pm 7.02$} \\
\hline $\operatorname{Rep} 2$ & 1 & 15 & 76 & 26 & \\
\hline $\operatorname{Rep} 3$ & 1 & 15 & 106 & 12 & \\
\hline Rep 1 & 2 & 15 & 107 & 23 & \multirow[t]{3}{*}{$22.0 \pm 1.73$} \\
\hline Rep 2 & 2 & 15 & 106 & 20 & \\
\hline Rep 3 & 2 & 15 & 107 & 23 & \\
\hline Rep 1 & 3 & 15 & 103 & 9 & \multirow[t]{3}{*}{$12.53 \pm 3.83$} \\
\hline Rep 2 & 3 & 15 & 108 & 16.6 & \\
\hline Rep 3 & 3 & 15 & 102 & 12 & \\
\hline
\end{tabular}

Figure 11. Average leaching efficiencies of three concentrations of acetic acid / hydroxylamine hydrochloride on $\mathrm{U}_{3} \mathrm{O}_{8}$-spiked sand.

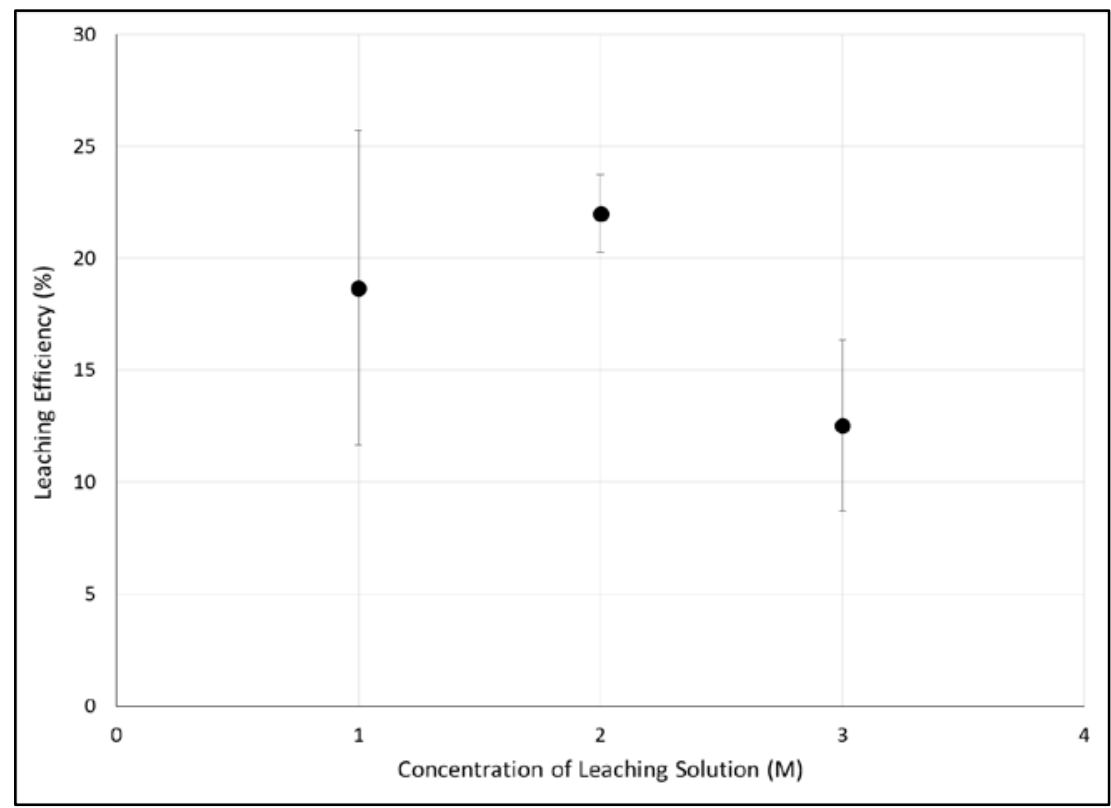


The calculated efficiency varies from sample to sample within triplicate leaching experiments. Statistically, the differences in the mean values among the three treatment groups are not great enough to exclude the possibility that the observed differences are due to random sampling variability. An analysis of variance (ANOVA) calculated that there was not a statistically significant difference between the three treatments $(\mathrm{P}=$ 0.965).

\subsubsection{Leaching of uranium from sand: U308 versus U02}

Sand samples were prepared using both $\mathrm{U}_{3} \mathrm{O}_{8}$ and $\mathrm{UO}_{2}$ to compare the leachability of two stable oxides of $U$, both of which may be found in the soil as the result of a DU aerosol. Table 7 and Figure 12 provide the calculated efficiencies using the postleaching spectra. T-test performed on the data in Table 7 passed the Shapiro-Wilkes normality $(\mathrm{P}=0.953)$ and Equal Variance $(P=0.089)$ tests. There is a statistically significant difference between the two treatments $(\mathrm{P}=0.019)$. The leaching efficiencies achieved for the $\mathrm{U}_{3} \mathrm{O}_{8}$ samples are similar to those presented in Table 6. The AA/ HAN leaching system is not as effective with the $\mathrm{UO}_{2}$ samples.

Table 7. Results of the leaching procedure using $1 \mathrm{M}$ acetic-acid solution with $\mathrm{U}_{3} \mathrm{O}_{8}$ and $\mathrm{UO}_{2}$.

\begin{tabular}{|c|c|c|c|c|c|}
\hline Sample ID & $\begin{array}{c}\text { Acetic-Acid } \\
\text { Concentration } \\
\text { (M) }\end{array}$ & $\begin{array}{c}\text { Percentage of } \\
0.3 \mathrm{M} \\
\text { Hydroxylamine } \\
\text { Hydrochloride } \\
(\%)\end{array}$ & $\begin{array}{l}\text { Leaching } \\
\text { Duration } \\
\text { (min) }\end{array}$ & $\begin{array}{l}\text { Lanthanum } \\
\text { Bromide } \\
\text { Measured } \\
\text { Efficiency (\%) }\end{array}$ & $\begin{array}{l}\text { Avg. Leaching } \\
\text { Efficiency } \\
(\%)\end{array}$ \\
\hline $\mathrm{U}_{3} \mathrm{O}_{8} \operatorname{Rep} 1$ & 1 & 15 & 85 & 18 & \multirow[t]{3}{*}{$18.67 \pm 7.02$} \\
\hline $\mathrm{U}_{3} \mathrm{O}_{8} \operatorname{Rep} 2$ & 1 & 15 & 76 & 26 & \\
\hline $\mathrm{U}_{3} \mathrm{O}_{8} \operatorname{Rep} 3$ & 1 & 15 & 106 & 12 & \\
\hline $\mathrm{UO}_{2} \operatorname{Rep} 1$ & 1 & 15 & 104 & -2 & \multirow[t]{3}{*}{$1.33 \pm 3.51$} \\
\hline $\mathrm{UO}_{2} \operatorname{Rep} 2$ & 1 & 15 & 100 & 5 & \\
\hline $\mathrm{UO}_{2} \operatorname{Rep} 3$ & 1 & 15 & 102 & 1 & \\
\hline
\end{tabular}


Figure 12. Comparison of average leaching efficiencies of $1 \mathrm{M}$ acetic acid / 15\% 0.3 M hydroxylamine hydrochloride on either $\mathrm{U}_{3} \mathrm{O}_{8}$ - or $\mathrm{UO}_{2}$-spiked sand.

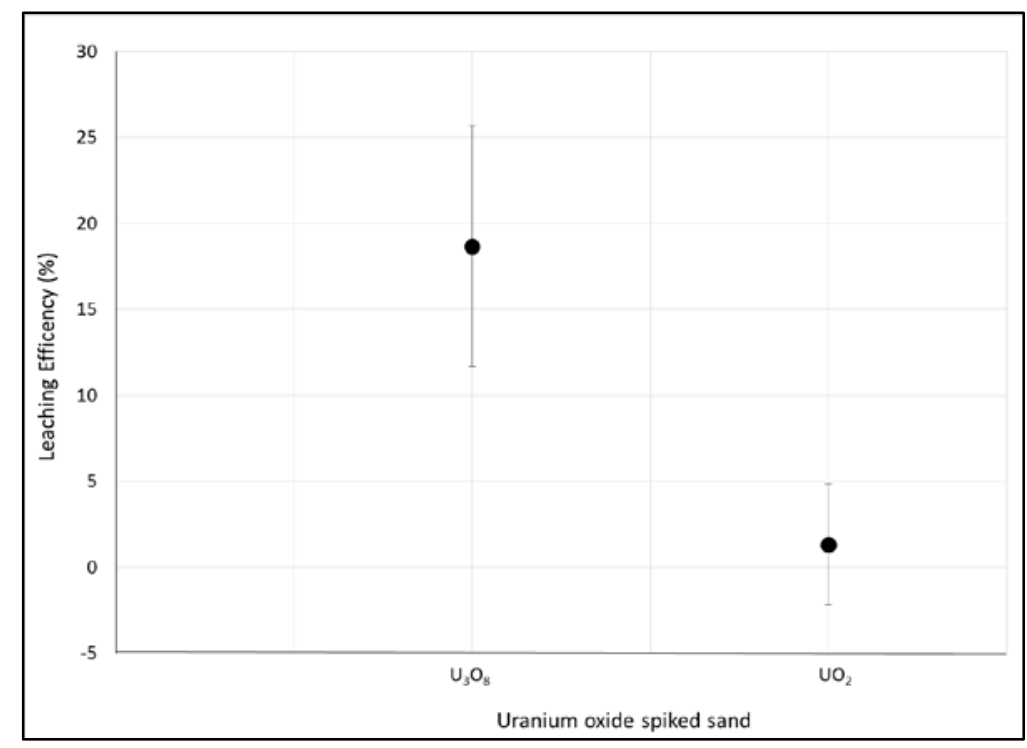

\subsubsection{Reduction of background radiation}

The researchers hypothesized that data consistency and variability could be improved by using shielding, to reduce background radiation, around the lanthanum bromide detector used for collecting the spectral data. Lead blocks were placed around the detector on all sides. The lead bricks formed a shield approximately 5.1 to $7.6 \mathrm{~cm}$ thick around the detector (Figure 13).

Figure 13. Lead shielding around the lanthanum bromide detector.

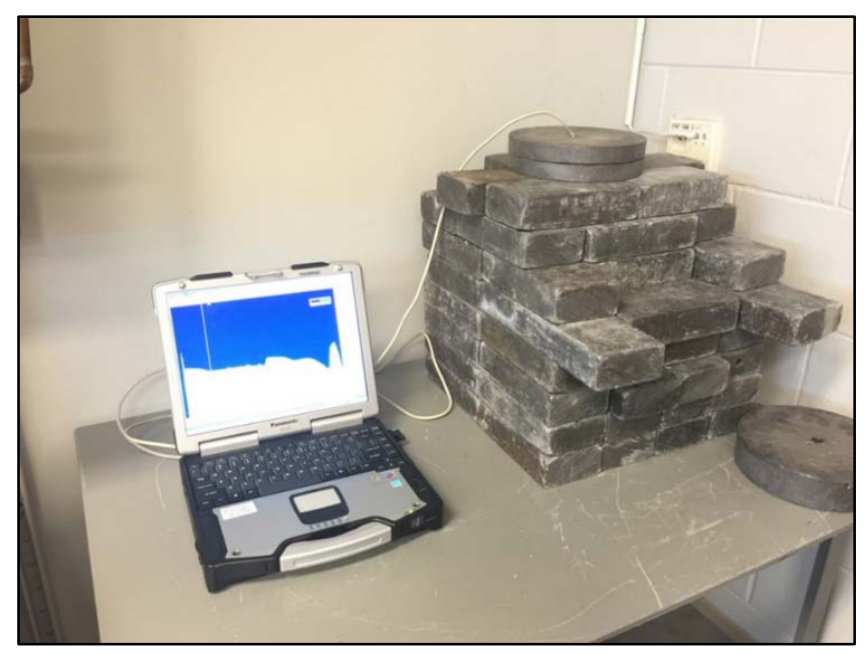


Background spectra were collected while under the lead shielding. These spectra were compared to previously collected background samples. As seen in Figure 14, lead shielding reduced background interference (shown by the blue line) by approximately $33 \%$.

Figure 14. Comparison of shielded background spectra (b/ue) to unshielded background spectra (red).

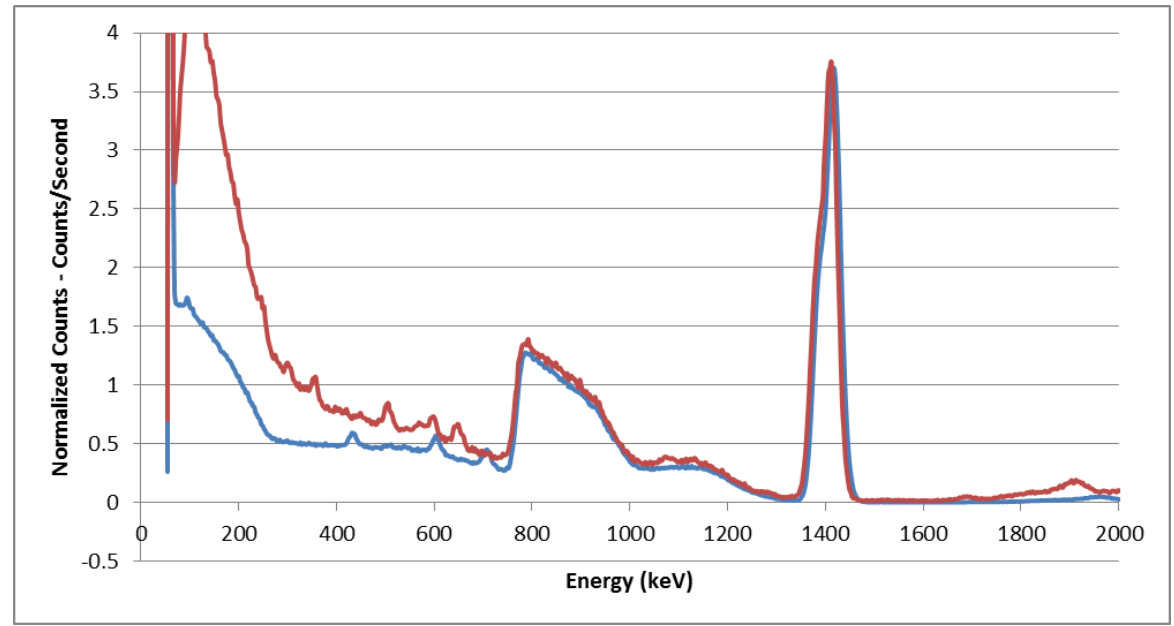

Note that in Figure 14, the difference in the spectra between the unshielded and shielded detectors is in the range of 300- $800 \mathrm{keV}$, the region of interest for U and DU compounds. The photopeaks in the unshielded background spectra can be attributed to background decay of $U$ and radon daughters found naturally in concrete structures. These photopeaks are removed after shielding, and three different photopeaks are present in the spectra in the shielded spectra. The source of these photopeaks is most likely from the interaction of the decay products of lanthanum-138 (La138) with the lead in the walls of the detector shielding, causing scatter back into the detector. The La-138 isotope is also a gamma emitter (1435 keV) which can clearly be seen in the spectra. This source of background radiation cannot be removed. In summary, the addition of shielding did not reduce background radiation significantly enough for use in measuring the small differences in U in pre- and postleaching U-spiked sand samples.

\subsubsection{Bench-scale testing using ICP-MS}

Leach testing was performed at bench scale, and chemical analysis was performed on all samples that were generated during leach testing. Table 8 
describes samples generated during a single leach test. All leaching was conducted using AA and Han. The AA concentration varied according to the test. All HAN concentrations were $15 \%$ of a $0.3 \mathrm{M}$ solution. The variables in this test were the leachate concentration and the mass of $U$ in the soil. Samples titled "Control" were not leached and were used to calculate leaching efficiency.

Table 8. Test matrix of bench-scale soil leach testing of $\mathrm{UO}_{2}$ with uranium mass and leachate concentrations as test variables.

\begin{tabular}{|c|c|c|c|c|c|}
\hline Sample ID & $\begin{array}{l}\text { Leach } \\
\text { Duration } \\
\text { (min) }\end{array}$ & $\begin{array}{c}\text { Acetic-Acid } \\
\text { Concentration } \\
\text { (M) }\end{array}$ & $\begin{array}{c}\text { Mass of } \\
\mathrm{UO}_{2}(\mathrm{~g})\end{array}$ & $\begin{array}{l}\text { Mass of } \\
\text { Uranium } \\
\text { (g) }\end{array}$ & $\begin{array}{c}\text { Uranium } \\
\text { Concentration } \\
(\mathrm{g} / \mathrm{L})\end{array}$ \\
\hline Set 1, Rep 1 & 113 & 1 & 0.227 & 0.200 & 1.001 \\
\hline Rep 2 & 116 & 1 & 0.227 & 0.200 & 1.002 \\
\hline Rep 3 & 110 & 1 & 0.227 & 0.200 & 1.001 \\
\hline Control & - & - & 0.227 & 0.200 & 1.001 \\
\hline Set $2, \operatorname{Rep} 1$ & 119 & 2 & 0.227 & 0.200 & 1.001 \\
\hline Rep 2 & 115 & 2 & 0.227 & 0.199 & 1.000 \\
\hline Rep 3 & 116 & 2 & 0.227 & 0.200 & 1.002 \\
\hline Control & - & - & 0.227 & 0.200 & 1.001 \\
\hline Set 3, Rep 1 & 119 & 3 & 0.227 & 0.200 & 1.001 \\
\hline $\operatorname{Rep} 2$ & 127 & 3 & 0.227 & 0.200 & 1.001 \\
\hline Rep 3 & 118 & 3 & 0.227 & 0.200 & 1.001 \\
\hline Control & - & - & 0.227 & 0.200 & 1.001 \\
\hline Set $4, \operatorname{Rep} 1$ & 113 & 1 & 0.454 & 0.400 & 2.002 \\
\hline Rep 2 & 116 & 1 & 0.454 & 0.400 & 2.000 \\
\hline Rep 3 & 110 & 1 & 0.454 & 0.399 & 2.000 \\
\hline Control & - & - & 0.454 & 0.400 & 2.001 \\
\hline Set 5 , Rep 1 & 119 & 2 & 0.454 & 0.400 & 2.002 \\
\hline Rep 2 & 115 & 2 & 0.454 & 0.400 & 2.001 \\
\hline Rep 3 & 116 & 2 & 0.454 & 0.400 & 2.001 \\
\hline Control & - & - & 0.454 & 0.400 & 2.002 \\
\hline Set 6 , Rep 1 & 119 & 3 & 0.454 & 0.400 & 2.001 \\
\hline $\operatorname{Rep} 2$ & 127 & 3 & 0.454 & 0.400 & 2.001 \\
\hline Rep 3 & 118 & 3 & 0.454 & 0.400 & 2.001 \\
\hline Control & - & - & 0.454 & 0.400 & 2.000 \\
\hline
\end{tabular}

The leaching procedure used to prepare these samples is as follows: 
1. Glass wool was placed at the bottom of the soil column to act as a filter for the sand.

2. The sand sample was poured into the soil column.

3. The column was filled with leaching solution and soaked for $10 \mathrm{~min}$. During this time, the column was repeatedly tapped to remove as much of the air within the column as possible.

4. A $125 \mathrm{ml}$ bottle was placed under the valve on the soil column.

5. The bottom valve was slowly opened. A flow rate of approximately one pore volume in 20 min was desired. This valve was adjusted throughout the leaching process to maintain this flow rate.

6. Six pore volumes (approximately $88 \mathrm{ml}$ each) were collected.

7. The top valve on the soil column was closed when the sixth pore volume was started to reduce the amount of remaining leachate at the end of leach testing.

8. The bottom valve on the soil column was closed after the sixth pore volume was collected.

9. Another $125 \mathrm{ml}$ bottle was placed under the bottom valve on the soil column.

10. The bottom valve on the soil column was opened all the way to drain the remaining leachate.

11. The bottom valve was closed.

12. The column was removed from its holder, and the wet sand was poured from the column into a large weighing boat.

13. The glass wool was removed from the bottom of the soil using a long pair of tongs.

14. The column was dried for $24 \mathrm{hr}$. Sand clinging to the side of the column was removed after the column had dried completely.

15. The weighing boat was placed in an oven at approximately $65.6^{\circ} \mathrm{C}$ overnight to dry.

16. The boat was removed from the oven and was left to cool for $1 \mathrm{hr}$.

17. The remaining sand from the soil column was slowly poured into the weighing boat, and the column was given several taps to remove as much sand as possible.

18. The sand and glass wool were poured into a clean bottle.

19. The column was washed twiœe with $75 \mathrm{ml}$ of leftover AA from the leaching process and rinsed twice with $50 \mathrm{ml}$ of clean water. All of the wash and rinse liquid was collected.

20. The weighing boat was rinsed with leftover AA, and the liquid was collected. 
21. All of the sample bottles were placed into Ziploc bags and put in a 5 gal. bucket for storage until analysis.

Select samples were analyzed for U concentrations by using ICP-MS. The ICP-MS data was used to calculate the total efficiency of the U removal during the leaching process (Table 9).

Table 9. Uranium removal through heap leaching of $\mathrm{UO}_{2}$-contaminated soil based on ICP-MS sample analysis.

\begin{tabular}{|c|c|c|c|}
\hline $\begin{array}{l}\text { Mass of } \mathrm{UO}_{2} \\
\text { (g) }\end{array}$ & $\begin{array}{l}\text { Acetic-Acid } \\
\text { Concentration } \\
\text { (M) }\end{array}$ & $\begin{array}{c}\text { \% Removal of Uranium } \\
\text { Based on Preleach } \\
\text { Balance and ICP-MS } \\
\text { Leachate Data }\end{array}$ & $\begin{array}{c}\text { \% Removal } \\
\text { (Avg.) }\end{array}$ \\
\hline 0.2271 & 1 & 2.91 & * \\
\hline 0.2272 & 2 & 2.98 & * \\
\hline 0.2272 & 3 & 2.98 & * \\
\hline 0.4542 & 1 & 2.92 & \multirow[t]{3}{*}{$2.96 \pm 0.04$} \\
\hline 0.4538 & 1 & 2.95 & \\
\hline 0.4537 & 1 & 3.00 & \\
\hline 0.4542 & 2 & 3.00 & \multirow[t]{3}{*}{$3.05 \pm 0.08$} \\
\hline 0.4540 & 2 & 3.01 & \\
\hline 0.4541 & 2 & 3.15 & \\
\hline 0.4540 & 3 & 3.19 & \multirow[t]{3}{*}{$3.13 \pm 0.06$} \\
\hline 0.4539 & 3 & 3.14 & \\
\hline 0.4540 & 3 & 3.07 & \\
\hline
\end{tabular}

* single sample, no average possible

Note: All leaching solutions also contained $15 \%(\mathrm{v} / \mathrm{v})$ of a $0.3 \mathrm{M}$ HAN solution

ICP-MS data was consistent among each sample set and shows that only about $3 \%$ of the $U$ was being leached under these conditions. Also, the leaching efficiency is nearly identical for soil spiked with the lower $(0.2 \mathrm{~g})$ or the higher $(0.4 \mathrm{~g})$ mass of $\mathrm{UO}_{2}$. However, an all pairwise multiple comparison test using the Holm-Sidak method determined that the leaching efficiencies obtained using the $3 \mathrm{M}$ AA are significantly different from those obtained using the $1 \mathrm{M}$ or $2 \mathrm{MAA}(\mathrm{P}=0.044$, significance interval $=$ 0.05). These calculated leaching efficiencies are very similar to those presented in Table 7, which were determined using the liquid scintillation detector. The results support the general unleachability of $\mathrm{UO}_{2}$ with $\mathrm{AA} / \mathrm{HAN}$. 


\subsubsection{Bench-scale testing with DU-contaminated soil}

Soil from a location where DU munitions have been fired was collected and passed through a \#100 sieve (150 um mesh). Four replicate samples, each with $275 \mathrm{~g}$ of contaminated soil, were created. Three of the samples were leached with $3 \mathrm{M}$ AA with 15\% (v/v) 0.3 HAN solution: DUS-1*, DUS2 , and DUS-3. The fourth soil sample served as a control and was not leached. The HPGe spectra were collected of each sample before and after the leaching procedure to determine the overall leaching efficiency.

The leaching procedures previously used for bench-scale soil leaching were modified to account for the low hydraulic conductivity of the soil. Six pore volumes of leaching solution were added to each soil column (two pore volumes each time for three additions). The bottom valve on the column was left open to allow the leaching solution to drip continuously over a period of $12-24 \mathrm{hr}$.

The leachate samples contained approximately $176 \mathrm{ml}$ of leachate. One pore volume was $88 \mathrm{ml}$. Calculations estimating the amount of $U$ in each leaching solution were performed using the counts obtained from one pore volume $(88 \mathrm{ml})$ as the standard. Table 10 provides the results of the leaching efficiencies.

Table 10. Efficiency of DU-contaminated soil leaching.

\begin{tabular}{|l|c|c|c|c|}
\hline $\begin{array}{c}\text { DU- } \\
\text { Contaminated } \\
\text { Field Soil }\end{array}$ & $\begin{array}{c}\text { Initial Mass of } \\
\mathbf{U} \text { in Soil } \\
(\mathbf{g})\end{array}$ & $\begin{array}{c}\text { U Mass Remaining in } \\
\text { Soil Sample after } \\
\text { Leaching } \\
(\mathbf{g})\end{array}$ & $\begin{array}{c}\text { Total Mass of U in } \\
\text { Leachate in One Pore } \\
\text { Volume } \\
(\mathbf{g})\end{array}$ & $\begin{array}{c}\text { \% of U } \\
\text { Removed }\end{array}$ \\
\hline Rep 1 & 1.02 & 0.37 & 0.85 & 84 \\
\hline Rep 2 & 1.02 & 0.36 & 0.73 & 71 \\
\hline Rep 3 & 1.02 & 0.34 & 0.83 & 81 \\
\hline Average & & 0.36 & 0.80 & 79 \\
\hline Stdev & & 0.01 & 0.07 & 6.53 \\
\hline
\end{tabular}

The results show that the AA/ HAN leaching solution can remove a significant portion of the U. DU in soil is more easily leached using the AA/ HAN solution than either $\mathrm{UO}_{2}$ or $\mathrm{U}_{3} \mathrm{O}_{8}$. Leaching efficiencies of $79 \%$ were

* DUS = depleted uranium soil 
achieved with DU compared to $20 \%$ for $\mathrm{U}_{3} \mathrm{O}_{8}$ and $3 \%$ for $\mathrm{UO}_{2}$. Further testing was undertaken to determine if this efficiency could be improved.

\subsubsection{Hydrochloric-acid presoak leaching efficiency}

Soil samples composed of $150 \mathrm{~g}$ sand doped with $0.5 \mathrm{~g}$ of $\mathrm{UO}_{2}$ or $\mathrm{U}_{3} \mathrm{O}_{8}$ were generated as described previously and were soaked in a hydrochloricacid $(\mathrm{HCl})$ solution to convert $\mathrm{U}$ oxides in the soils to a more leachable form. In addition, samples containing DU that had previously undergone the leaching procedure, DUS-2 and DUS-3, were split to create four soil samples with approximately $120 \mathrm{~g}$ in each sample.

The samples containing $\mathrm{UO}_{2}, \mathrm{U}_{3} \mathrm{O}_{8}$ or once-leached DU-contaminated range soils were placed in the soil columns and soaked with $3 \mathrm{M} \mathrm{HCl}$ for 1 day, 7 days, or 14 days. The $\mathrm{HCl}$ solutions were then drained, and the soaked soil samples underwent the leaching procedures previously described using $3 \mathrm{M}$ acetic-acid solutions.

To estimate leaching efficiency, the soil samples were analyzed for total counts by using an HPGe detector before and after the leaching procedure. The leachate solutions were also analyzed to complete a mass balance. In this study, the efficiency was calculated using two different methods. The first method compared the total counts in the pre- and postleached soil samples. The second method estimated the amount of $U$ within the leachate samples and compared that to the amount of $U$ in the sample before leaching. Efficiency based on HPGe counting of the leachate solutions exhibited the least variability and was used to generate the data presented in Table 11 and in Figure 19.

In Table 9 (Section 2.4.4), leaching of $\mathrm{UO}_{2}$-spiked sand with $3 \mathrm{M}$ AA and no acid pretreatment yielded an average 3\% U removal. As seen in Table 11 and Figure 15, U removal with the $24 \mathrm{hr}$ acid presoak is closer to $21.2 \%$, a sevenfold increase. This increase in U leachability indicates conversion of low leachability $\mathrm{UO}_{2}$ during the $\mathrm{HCl}$ soaking. Leaching efficiency of $\mathrm{U}_{3} \mathrm{O}_{8}$ also increased with $\mathrm{HCl}$ presoaking but not to such an extent. Referring to Table 6 and Table 11, U leaching from $\mathrm{U}_{3} \mathrm{O}_{8}$-spiked sand with $3 \mathrm{M}$ AA and no acid presoak yielded $12.5 \%$ removal of U. Removal with the HCl presoak was approximately $47.37 \%$, a 3.8-fold increase. 
Unlike the $\mathrm{UO}_{2}$ - and $\mathrm{U}_{3} \mathrm{O}_{8}$-spiked sand samples, the $\mathrm{DU}$ firing range soil samples had already been leached once with 3 MAA / 15\% HAN prior to the HCl presoak treatment. These samples continued to show leaching of $\mathrm{U}$ following $\mathrm{HCl}$ pretreatment that corresponds to a leaching efficiency of approximately $32 \%$. This indicates that $\mathrm{HCl}$ conversion of poor leaching $\mathrm{U}$ oxides to more leachable forms also occurred during the $\mathrm{HCl}$ treatment of the field-contaminated soil.

Table 11. Leaching efficiency of uranium from soil with an added hydrochloric-acid presoak.

\begin{tabular}{|l|c|c|c|c|}
\hline Soil Type & $\begin{array}{c}\text { Uranium } \\
\text { Compound }\end{array}$ & $\begin{array}{c}\mathrm{HCl} \mathrm{Soak} \\
\text { Time }\end{array}$ & $\begin{array}{c}\text { Efficiency Based on Soil } \\
\text { Measurements (\%) }\end{array}$ & $\begin{array}{c}\text { Efficiency Based on } \\
\text { Leachate Solutions (\%) }\end{array}$ \\
\hline Sand & $\mathrm{UO}_{2}$ & $24 \mathrm{hr}$ & 27.04 & 7.75 \\
\hline Sand & $\mathrm{UO}_{2}$ & 1 week & 43.58 & 13.83 \\
\hline Sand & $\mathrm{UO}_{2}$ & 2 weeks & 32.23 & 19.27 \\
\hline Sand & $\mathrm{U}_{3} \mathrm{O}_{8}$ & $24 \mathrm{hr}$ & 52.96 & 35.66 \\
\hline Sand & $\mathrm{U}_{3} \mathrm{O}_{8}$ & 1 week & 61.00 & 52.43 \\
\hline Sand & $\mathrm{U}_{3} \mathrm{O}_{8}$ & 2 weeks & 65.53 & 59.45 \\
\hline Field Soil & $\mathrm{DU}$ & $24 \mathrm{hr}$ & 68.27 & 12.33 \\
\hline Field Soil & $\mathrm{DU}$ & 1 week & 30.65 & 14.79 \\
\hline Field Soil & $\mathrm{DU}$ & 2 weeks & 41.46 & 13.90 \\
\hline
\end{tabular}

Figure 15. Leach efficiency for uranium-spiked sand and field-contaminated soil after hydrochloric-acid presoak.

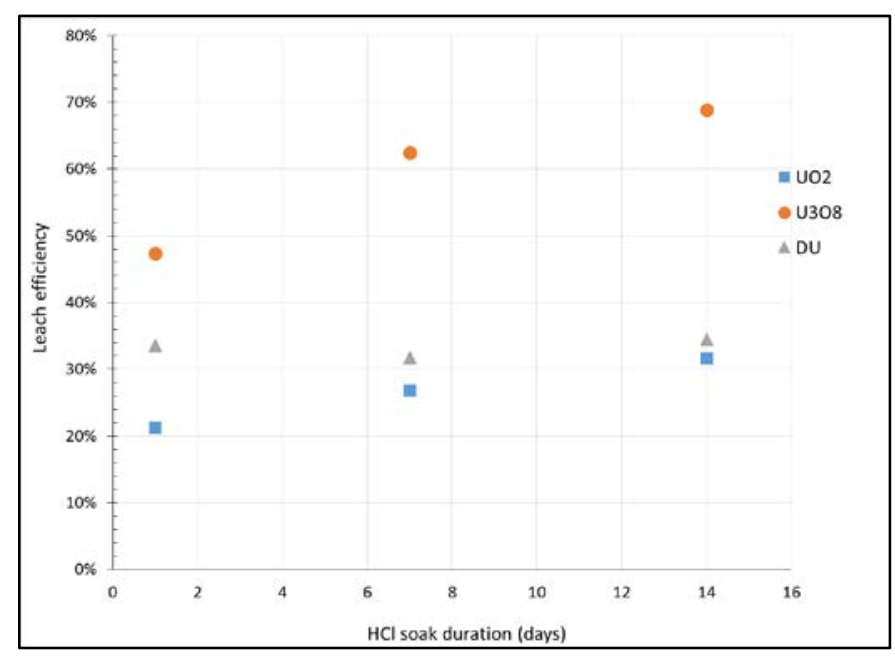

Figure 15 shows that the leach efficiency increases with soaking time for both $\mathrm{UO}_{2}-$ and $\mathrm{U}_{3} \mathrm{O}_{8}$-spiked sands. This increase is not observed for the field-contaminated soil. One hypothesis suggests that this difference is due to the buffering capacity of the field-site soil. 
Table 12 compares the amount of U removed in individual leaching steps following various times of acid presoak. For $\mathrm{UO}_{2}$-spiked sand and the DU range soils that were leached once, Leach 1 accounted for the majority of $U$ removal. For $\mathrm{U}_{3} \mathrm{O}_{8}$, a significant mass of $\mathrm{U}$ was observed in both the first and second leach steps. No significant removal of $U$ was accomplished in subsequent leaching steps. This observation is the same for a 7-day and a 14-day acid presoak.

Table 12. Comparison of the uranium removed (\%) in individual leaching steps following acid presoak times of varying duration for $\mathrm{U}_{3} \mathrm{O}_{8}$ - and $\mathrm{UO}_{2}$-spiked sand and a preleached DU-contaminated field soil.

\begin{tabular}{|c|c|c|c|c|}
\hline \multirow[b]{2}{*}{ Leach step } & \multirow{2}{*}{$\begin{array}{c}\text { Duration of acid } \\
\text { presoak }\end{array}$} & \multicolumn{3}{|c|}{ \% Uranium removed } \\
\hline & & $\mathrm{U}_{3} \mathrm{O}_{8}$ & $\mathrm{UO}_{2}$ & DU field soil \\
\hline Leach 1 & \multirow[t]{5}{*}{1 day } & 25.90 & 7.31 & 10.88 \\
\hline Leach 2 & & 9.66 & 0.30 & 0.48 \\
\hline Leach 3 & & 0 & 0 & 0 \\
\hline Leach 4 & & 0 & 0.01 & 0.54 \\
\hline Leach 5 & & 0.10 & 0.13 & 0.43 \\
\hline Leach 1 & \multirow[t]{5}{*}{7 days } & 37.77 & 8.49 & 8.87 \\
\hline Leach 2 & & 13.59 & 4.55 & 4.76 \\
\hline Leach 3 & & 0.37 & 0.02 & 0.77 \\
\hline Leach 4 & & 0.6 & 0.20 & 0.31 \\
\hline Leach 5 & & 0.11 & 0.57 & 0.08 \\
\hline Leach 1 & \multirow[t]{5}{*}{14 days } & 35.67 & 12.94 & 8.89 \\
\hline Leach 2 & & 22.44 & 5.09 & 4.57 \\
\hline Leach 3 & & 0.4 & 0.53 & 0 \\
\hline Leach 4 & & 0.94 & 0.2 & 0.16 \\
\hline Leach 5 & & 0 & 0.51 & 0.31 \\
\hline
\end{tabular}

These results show that the remaining U material in the DU-contaminated soil after being leached acts like $\mathrm{UO}_{2}$. The leaching data also shows that $\mathrm{HCl}$ presoaks can be used to boost leaching efficiencies. The DU soil sample was leached several more times to see if leaching would continue to remove U from the soil column. Hydrochloric-acid soaks ( $24 \mathrm{hr}$ ) were performed after the 12th, 15th, and 18th leach. Table 13 and Figure 16 show the results for each leach. These results confirm that $\mathrm{HCl}$ is responsible for increased leachability of U from the soil column. However, it does not appear to directly improve the leachability of $U$ after the second soak. Subsequent $\mathrm{HCl}$ solutions could potentially be used to increase overall leaching 
efficiency, but it appears that this would only be functional for a total of three leaches. Analyzing the soil samples pre- and postleaching, approximately $79 \%$ of the $U$ was removed from the soil after 4 acid treatments and 21 additional leaches.

Table 13. Results of extended leaching of DU-contaminated soil.

\begin{tabular}{|l|c|l|c|}
\hline \multicolumn{1}{|c|}{ Sample ID } & Efficiency (\%) & \multicolumn{1}{c|}{ Sample ID } & Efficiency (\%) \\
\hline Acid Drain 1 & 10.88 & Acid Drain 2 & 12.86 \\
\hline Leach 1 & 0.48 & Leach 13 & 2.54 \\
\hline Leach 2 & 0.00 & Leach 14 & 1.53 \\
\hline Leach 3 & 0.54 & Leach 15 & 0.17 \\
\hline Leach 4 & 0.43 & Acid Drain 3 & 2.26 \\
\hline Leach 5 & 1.78 & Leach 16 & 1.49 \\
\hline Leach 6 & 0.40 & Leach 17 & 0.00 \\
\hline Leach 7 & 1.54 & Leach 18 & 0.00 \\
\hline Leach 8 & 0.00 & Acid Drain 4 & 0.24 \\
\hline Leach 9 & 0.00 & Leach 19 & 0.36 \\
\hline Leach 10 & 0.78 & Leach 20 & 0.07 \\
\hline Leach 11 & 0.22 & Leach 21 & 0.19 \\
\hline Leach 12 & 0.46 & & \\
\hline
\end{tabular}

Figure 16. Results of extended leaching with hydrochloric-acid soaking of DUcontaminated field soil.

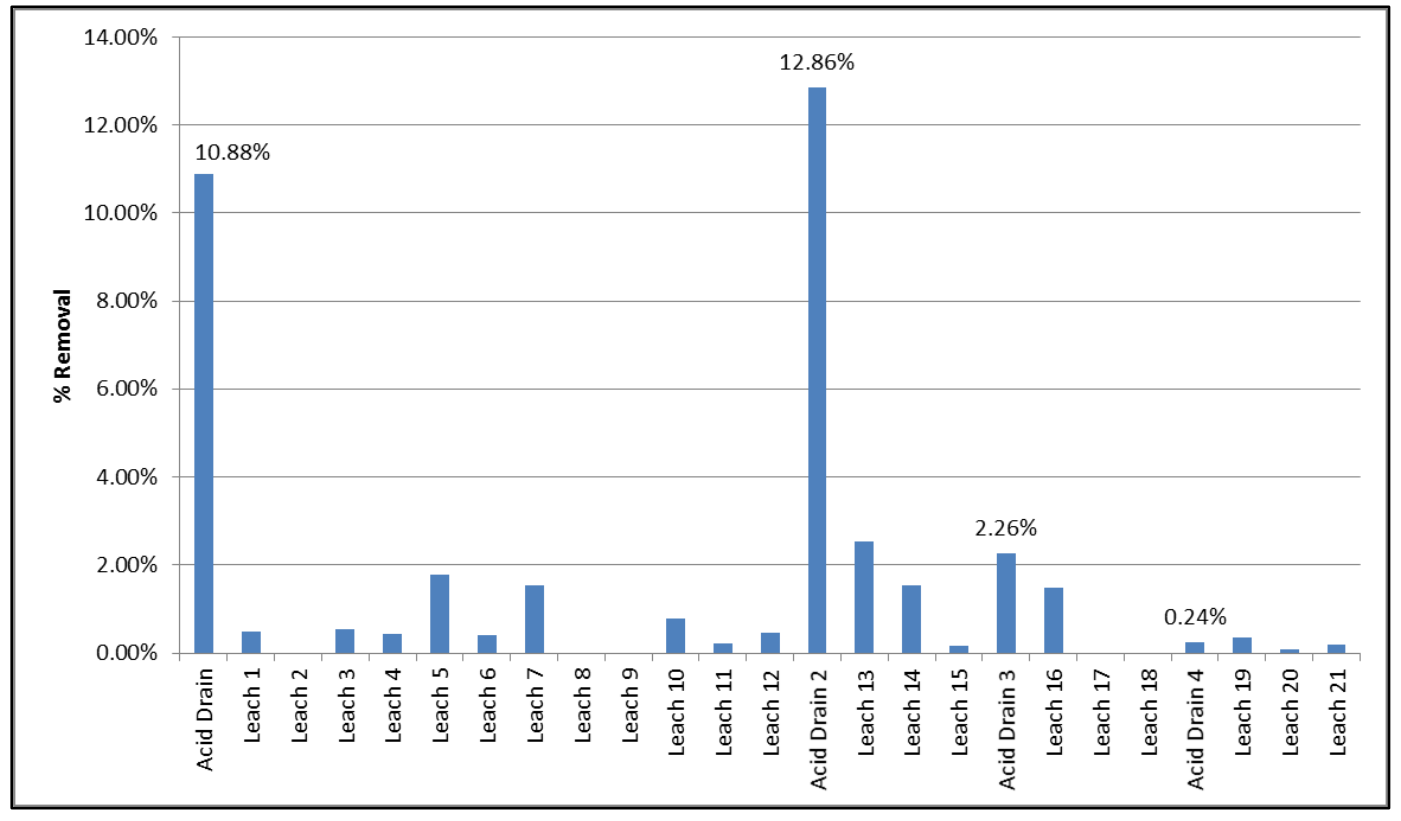




\section{Optimization of Bench-Scale Chemical Leaching}

\subsection{Objective}

The results from the previous chapter provide information about the performance of the leaching solutions in order to determine an optimum leaching solution for $U$ removal. The primary objective of this investigation was to identify the optimum AA-based leaching solution for U removal from DU-contaminated soils and to compare these results with solutions that have been used in industry for processing $\mathrm{U}$ ore.

\subsection{Experimental design}

The focus of the experimental design was to develop a leaching procedure that would be easy to replicate and would minimize the amount of radioactive-waste generated. Acetic acid with hydroxylamine hydrochloride (AA/HAN) was the primary leaching reagent of interest in this investigation. The performance of a variety of other leaching solutions common to the ore-processing industry were used for comparison.

An extensive literature review identified that there is no consistent, universal, or uniform methodology in any industry or laboratory setting to identify the performance characteristics of leaching solutions for U removal. Sample sizes in the literature range from one gram to several kilograms. Methodologies for conducting leaches also varied widely (Choy 2006; Francis and Dodge 1998; Mason et al. 1997; Guettaf et al. 2009). The large variations in experimental designs made it difficult to effectively compare results found in literature. Techniques and testing methods were taken from literature when applicable to meet the design goals.

\subsection{Materials and methods}

\subsubsection{Uranium measurements}

HPGe detectors are the preferred radiation detector type for isotope identification and gamma-ray measurements. Therefore, this study used an HPGe spectroscopy system for the data collection portion. Instead of fo- 
cusing on total counts, this chemical leaching optimization efficiency experiment analyzed individual photopeaks from the gamma-ray spectra. Radiation measurements from the decay of U-235 and daughter isotopes of U-238 were used to analyze the U contents of the soil samples. Highprecision gamma-ray spectrometry is required for measurements of both isotopes due to the large number of naturally occurring isotopes in the soil as well as the daughter products of the U isotopes. HPGe detectors excel at having very accurate energy resolution, which allows for discriminating and separating photopeaks in spectra. The HPGe detector used in this study was an ORTEC GMX30 Gamma-X coaxial HPGe detector fitted with a DWR-30 liquid nitrogen dewar flask that can hold $30 \mathrm{~L}$ of liquid nitrogen for a static holding time of 14 days (Figure 17).

Figure 17. HPGe detector system used for analysis of uranium in soil samples.

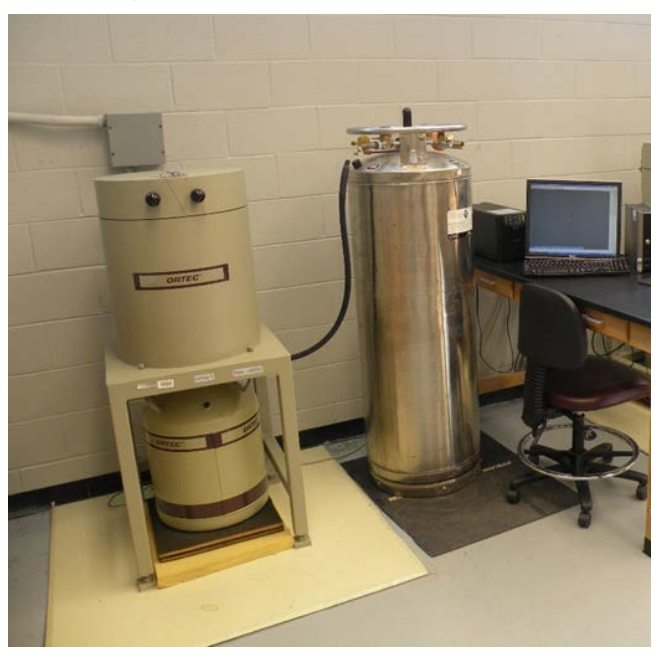

Table 14 presents the measured performance specifications for the HPGe detector. 
Table 14. Performance specifications for the HPGe detector used for detection of uranium in soil.

\begin{tabular}{l|c|}
\hline Specification & Measurement \\
\hline Resolution (FWHM) at 1.33 MeV & $1.8 \mathrm{keV}$ \\
\hline $\begin{array}{l}\text { Peak-to-Compton Ratio for Cobalt } \\
\text { (Co-60) }\end{array}$ & $68: 1$ \\
\hline Relative Efficiency at 1.33 MeV & $39.2 \%$ \\
\hline Peak Shape (FWTM/FWHM) & 1.84 \\
\hline Peak Shape (FWFM/FWHM) & 2.42 \\
\hline Amplifier Time Constant & $6 \mu \mathrm{s}$ \\
\hline MeV = Megaelectronvolt \\
FWHM = Full width half maximum \\
FWFM = Full width at fiftieth of maximum \\
FWTM = Full width at tenth of maximum
\end{tabular}

The detection efficiency of the GMX30 detector is significantly lower than the universal standard $3 \times 3$ sodium iodide $(\mathrm{NaI})$ or other type gamma-ray scintillator. The primary use of this detector is for energy resolution over the entire energy range ( $10 \mathrm{keV}-3 \mathrm{MeV}$ ) and low signal-to-background ratio (Knoll 2000). Spectra from soil samples can have an array of isotopes with $\mathrm{x}$-ray or gamma-ray emissions from a variety of isotopes in the soil. Each isotope has the potential of having more than one emission energy. The use of the HPGe detector allows gamma-ray energies to be easily resolved.

GammaVision software (ORTEC, USA) was used to control all aspects of the HPGe detector, including initializing data runs, stopping runs after a specified time, and saving spectra. The software was also used to verify that the detector was performing as specified and to ensure that energy calibrations were maintained. The primary photopeak of U-235 is the $185.7 \mathrm{keV}$ gamma ray and is used for data analysis purposes (Figure 18). The $143.8 \mathrm{keV}$ gamma ray is used as a secondary photopeak for validating results.

U leaching efficiency was estimated using a peak integration algorithm with background subtraction (Gilmore 2008) on the $185 \mathrm{keV}$ photon from U-235 and the $1001 \mathrm{keV}$ photon from Pa-234m, the primary photopeaks used for estimating $\mathrm{U}$ leaching efficiency. 
Figure 18. Screenshot depicting U-235 spectra in GammaVision with U235 photopeaks highlighted.

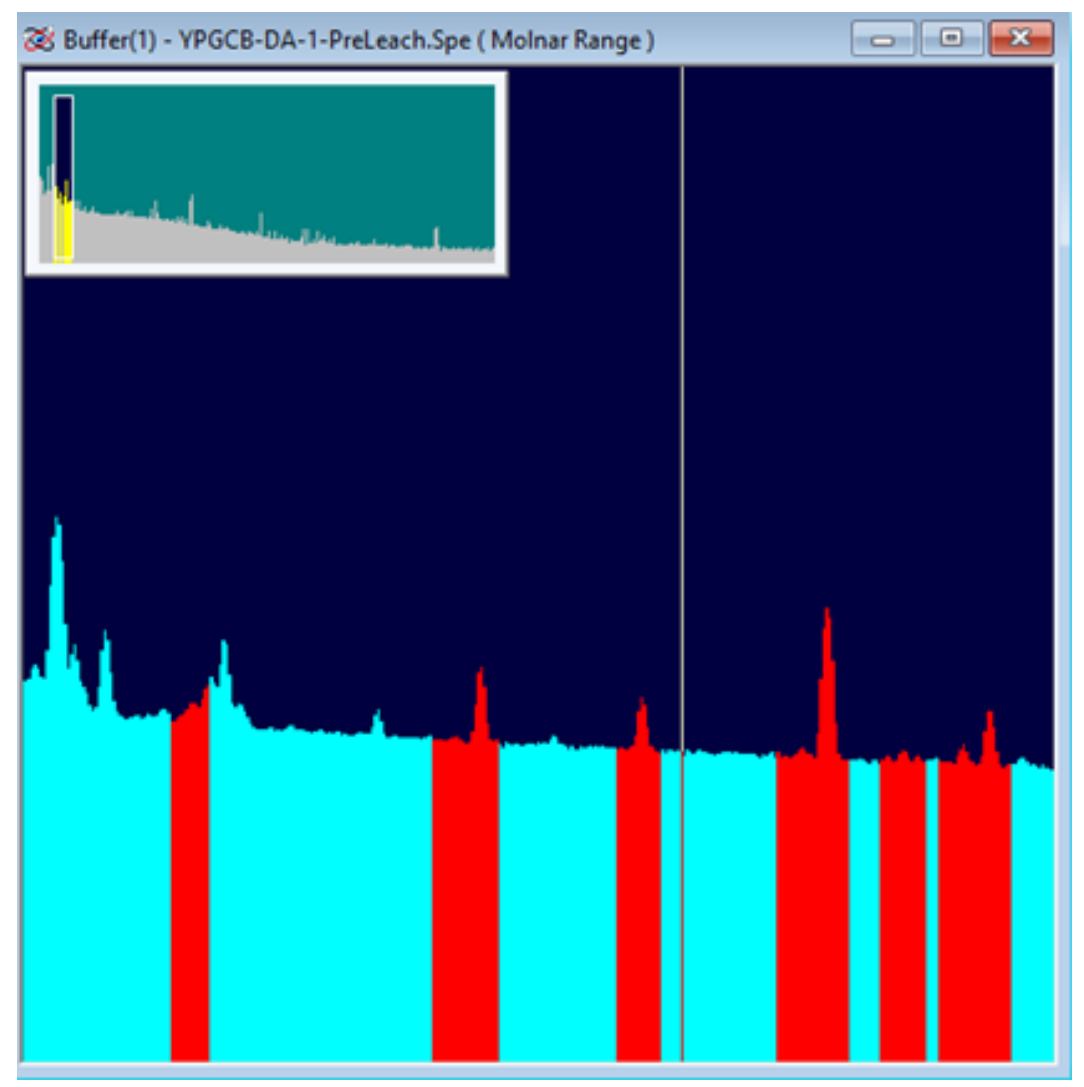

Equation (4) is used to perform the photopeak integration with background subtraction. Equation (5) gives the standard deviation for the area of the photopeak.

$$
\begin{gathered}
A=\sum_{i=L}^{U} C_{i}-n\left(\sum_{i=L-m}^{L-1} C_{i}+\sum_{i=U+1}^{U+1} C_{i}\right) / 2 m \\
\sigma=\sqrt{\sum_{i=L}^{U} C_{i}-n^{2}\left(\sum_{i=L-m}^{L-1} C_{i}+\sum_{i=U+1}^{U+1} C_{i}\right) / 4 m^{2}}
\end{gathered}
$$

Equation (4) calculates the total counts within the region of interest. The equation also calculates a linear fit to the background by using data to the left and right of the region of interest. The linear fit is used to subtract the background from the photopeak. This technique is very useful as it avoids 
having to collect separate background spectra, which removes another potential source of error. This technique is also useful when there are nuclides present with higher energy photopeaks. The higher energy photopeaks will produce a Compton plateau, introducing a higher background signal at lower energies. This integration technique avoids many potential issues associated with background radiation.

The team wrote software in MatLab to automate calculations for collected spectra and to ensure that each spectra is analyzed consistently. The software also generates figures of the spectrum and of each photopeak for U235, Pa-234m, and Bi-214 (bismuth-214). Figure 19 shows an example spectrum. Photopeaks from the $185 \mathrm{keV}$ gamma from U-235 and $1001 \mathrm{keV}$ gamma from $\mathrm{Pa}-234 \mathrm{~m}$ are isolated from the full spectra as seen in Figure 20 and Figure 21.

The software calculates and analyzes the area for several photopeaks for each isotope. Table 15 and Table 16 provide the photopeaks and their respective channel number from the spectrum file for U-235 and U-238, respectively. A spectrum report is created after the software has completed analyzing the sample (Figure 22). This report contains the full spectrum with counts for Pa-234m, U-235, and Bi-214 at several different photopeaks. The Bi-214 data is currently not used but can be used in future applications for potential DU discrimination routines.

Figure 19. Example of a full-energy spectrum using an ORTEC GMX30 Detector and MatLab data analysis software.

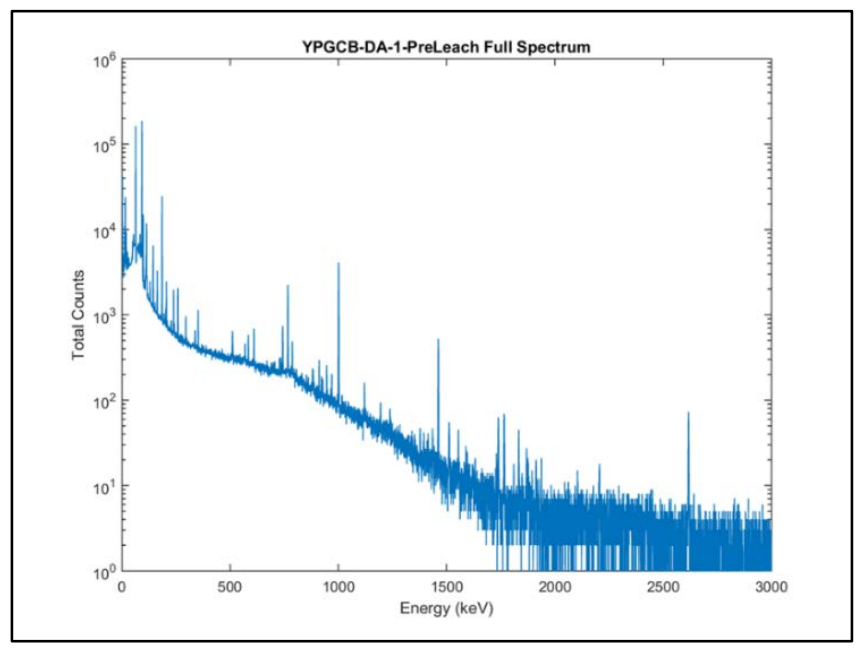


Figure 20. Example of a photopeak measured using an ORTEC GMX30 HPGe detector of the $185 \mathrm{keV}$ gamma ray emitted from U235.

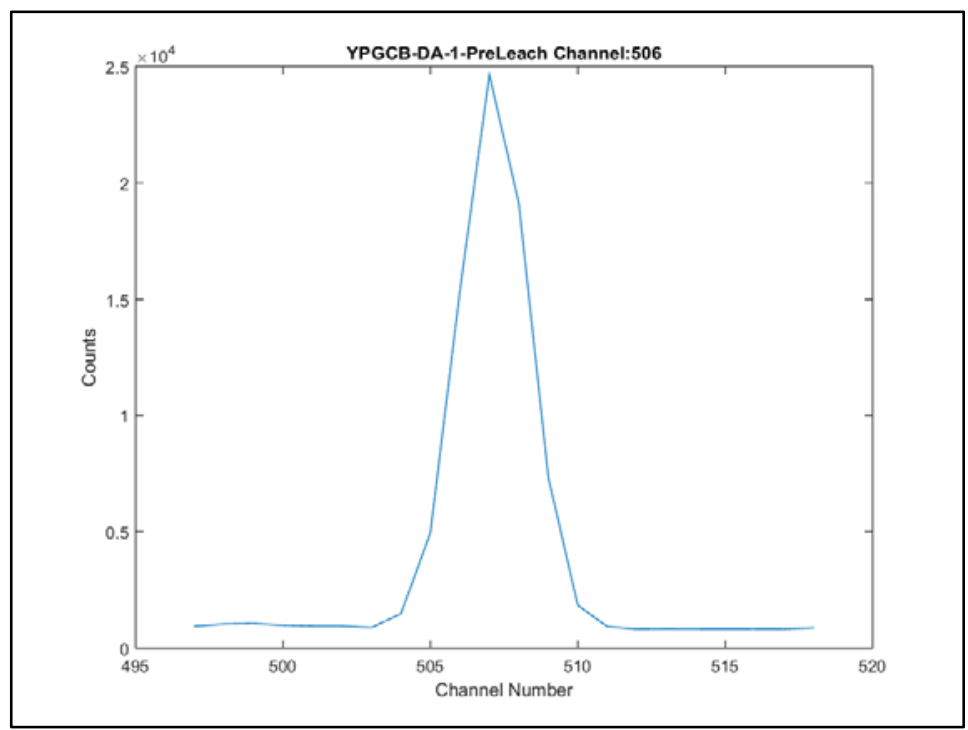

Figure 21. Example of a photopeak measured using an ORTEC GMX30 HPGe detector for the $1001 \mathrm{keV}$ gamma ray emitted from $\mathrm{Pa}-234 \mathrm{~m}$.

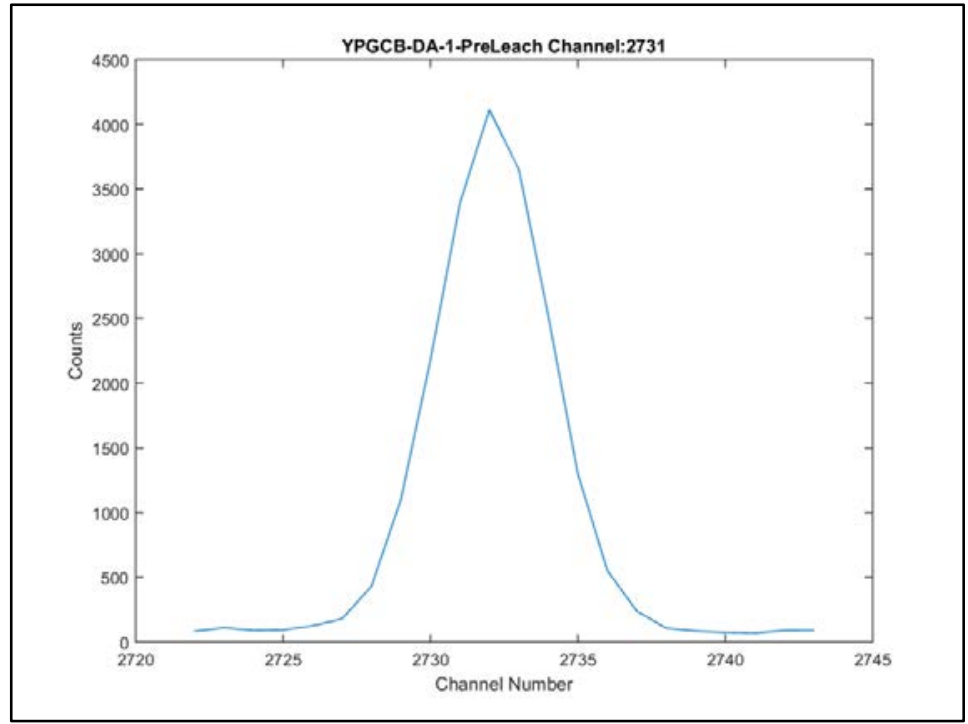

Table 15. Channel number and gamma-ray energy used in automated software for U-235.

\begin{tabular}{|l|c|}
\hline Energy (keV) & Spectrum Channel \\
\hline 143 & 391 \\
\hline 163 & 445 \\
\hline 185 & 506 \\
\hline 205 & 559 \\
\hline
\end{tabular}


Table 16. Channel number and gamma-ray energy used in automated software for U-238.

\begin{tabular}{|l|c|}
\hline Energy (keV) & Spectrum Channel \\
\hline 258.2 & 704 \\
\hline 742.8 & 2025 \\
\hline 766.4 & 2090 \\
\hline 786.3 & 2144 \\
\hline 1001.0 & 2731 \\
\hline
\end{tabular}

Figure 22. Example of a full gamma-ray spectrum analysis report.

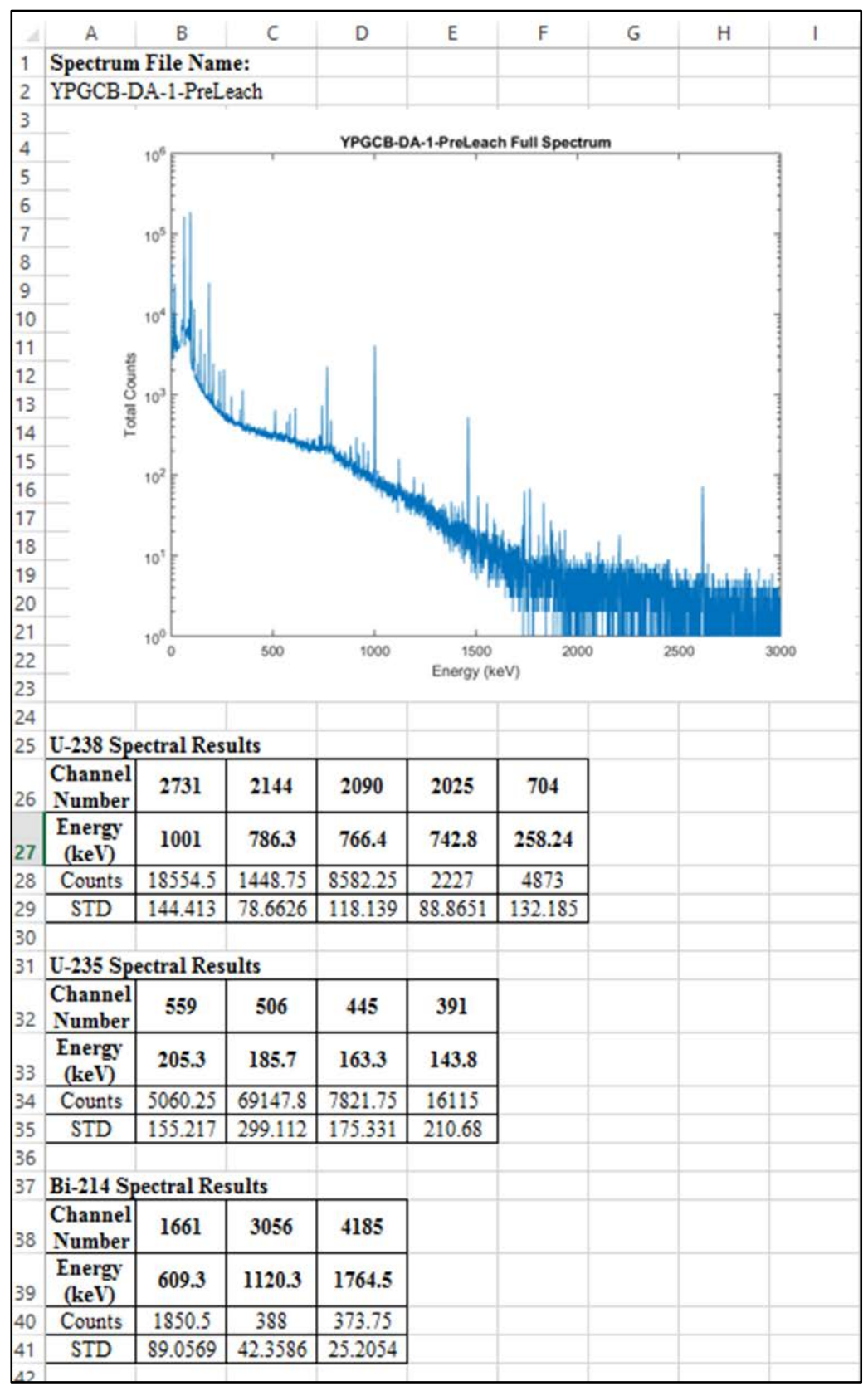


Photopeak data for U-235 and Pa-234m are then transferred to a spreadsheet to calculate the overall efficiencies (Figure 23) using data from both U-235 and Pa-234 photopeaks in Equation (6). The ratio between the photopeaks before and after leaching and the error propagation for each calculation are also calculated. A difference in ratio between pre- and postleaching spectra shows that secular equilibrium for Th-234 has been affected by the leaching solutions.

Figure 23. Example efficiency calculation.

\begin{tabular}{|c|c|c|c|c|c|c|c|c|c|}
\hline$\Delta$ & A & B & c & D & E & $\mathrm{F}$ & G & $\mathrm{H}$ & 1 \\
\hline 1 & & & & & & & & & \\
\hline 2 & & \multicolumn{8}{|c|}{ YPGCB-DA-1 } \\
\hline 3 & & \multicolumn{8}{|c|}{ 1 M Acetic Acid, 15\% 0.3M Hyrdrox. Hydroch. } \\
\hline 4 & & \multicolumn{3}{|c|}{$\mathrm{Pa}-234 \mathrm{M}(\mathrm{U}-238)$} & \multicolumn{3}{|c|}{$\mathrm{U}-235$} & \multicolumn{2}{|c|}{ Ratios } \\
\hline 5 & & \multicolumn{3}{|c|}{$1001 \mathrm{keV}$} & \multicolumn{3}{|c|}{$185 \mathrm{keV}$} & \multicolumn{2}{|c|}{$\mathrm{U}-238 / \mathrm{U}-235$} \\
\hline 6 & & Pre Leach & Post Leach & $\begin{array}{l}\text { Estimated } \\
\text { Efficiency }\end{array}$ & Pre Leach & Post Leach & $\begin{array}{l}\text { Estimated } \\
\text { Efficiency }\end{array}$ & Pre Leach & Post Leach \\
\hline 7 & Counts & 18554.5 & 12368 & $33.34 \%$ & 69147.8 & 26254 & $62.03 \%$ & 3.73 & 2.12 \\
\hline 8 & STD & 144.4 & \begin{tabular}{|l|}
118.6981466 \\
\end{tabular} & $0.41 \%$ & 299.1 & 196.084166 & $0.54 \%$ & 0.03 & 0.03 \\
\hline 9 & $\%$ Error & $0.78 \%$ & $0.96 \%$ & $1.24 \%$ & $0.43 \%$ & $0.75 \%$ & $0.86 \%$ & $0.89 \%$ & $1.22 \%$ \\
\hline
\end{tabular}

The most efficient solutions, including those with oxidants, from Table 4 (Section 1.1.2 of this report) were chosen for a second investigation. A large range of leaching times are also shown in Table 4 for each leaching efficiency. However, most literature and research reported here show that U dissolution occurs within the first $24 \mathrm{hr}$. A conservative $72 \mathrm{hr}$ leach duration was chosen for bench-scale testing. Table 17 presents the experimental matrix. 
Table 17. Experimental matrix of the second bench-scale leach test.

\begin{tabular}{|c|c|c|c|}
\hline Leaching Solution Composition & Pretreatment & $\begin{array}{l}\text { Leaching } \\
\text { Temp } \\
\left({ }^{\circ} \mathrm{C}\right)\end{array}$ & $\begin{array}{l}\text { Leach } \\
\text { Duration } \\
\text { (hr) }\end{array}$ \\
\hline $1 \mathrm{M} \mathrm{AA}, 15 \% 0.3 \mathrm{M}$ HAN & No & 20 & 72 \\
\hline $2 \mathrm{M} \mathrm{AA}, 15 \% 0.3 \mathrm{M}$ HAN & No & 20 & 72 \\
\hline $3 \mathrm{M} \mathrm{AA}, 15 \% 0.3 \mathrm{M}$ HAN & No & 20 & 72 \\
\hline 3 M AA, No HAN & No & 20 & 72 \\
\hline $3 \mathrm{M} \mathrm{AA}$, hydrogen peroxide $\left(\mathrm{H}_{2} \mathrm{O}_{2}\right)$ & No & 20 & 72 \\
\hline $3 \mathrm{M} \mathrm{AA}, \mathrm{MnO}_{2}$ & No & 20 & 72 \\
\hline $3 \mathrm{M} \mathrm{AA}, 15 \% 0.3 \mathrm{M} \mathrm{HAN}$ & No & 20 & 8 \\
\hline $3 \mathrm{M} \mathrm{AA}, 15 \% 0.3 \mathrm{M} \mathrm{HAN}$ & No & 20 & 16 \\
\hline 3 M AA, 15\% 0.3 M HAN & No & 20 & 24 \\
\hline $3 \mathrm{M} \mathrm{AA}, 15 \% 0.3 \mathrm{M} \mathrm{HAN}$ & No & 20 & 48 \\
\hline 3 M AA, 15\% 0.3 M HAN & $\begin{array}{c}\text { Yes, } 24 \mathrm{hr} \\
3 \mathrm{M} \mathrm{HCl}\end{array}$ & 20 & 72 \\
\hline 3 M AA, 15\% 0.3 M HAN & No & 40 & 72 \\
\hline $3 \mathrm{M} \mathrm{AA}, 15 \% 0.3 \mathrm{M} \mathrm{HAN}$ & No & 60 & 72 \\
\hline $0.3 \mathrm{M} \mathrm{C}_{6} \mathrm{H}_{8} \mathrm{O}_{7}$ & No & 20 & 72 \\
\hline $1 \mathrm{M} \mathrm{HNO}_{3}$ & No & 20 & 72 \\
\hline $1 \mathrm{M} \mathrm{H}_{2} \mathrm{SO}_{4}, 0.02 \% \mathrm{MnO}_{2}$ & No & 20 & 72 \\
\hline $0.1 \mathrm{M} \mathrm{NaHCO}_{3}, 15 \% \mathrm{H}_{2} \mathrm{O}_{2}$ & No & 20 & 72 \\
\hline $0.05 \mathrm{M} \mathrm{Na}_{2} \mathrm{CO}_{3} / 0.05 \mathrm{M} \mathrm{NaHCO}_{3}$ & No & 20 & 72 \\
\hline
\end{tabular}

\subsubsection{Test soil}

MSU-ICET has been involved with developing technology for the location and identification of DU-contaminated soils (Unz et al. 2011; Vaughn et al. 2011). Researchers from MSU-ICET obtained two 5 gal. buckets of soil contaminated with DU from a site where DU munitions have been used. All of the soil contained within the 5 gal. buckets was sieved through a \#100 sieve $(149 \mu \mathrm{m})$ to remove any large objects, including zero-valent U or large pieces of schoepite. A total of $1 \mathrm{~kg}$ of sieved soil was collected. The sieved soil was placed into a $4 \mathrm{~L}$ Nalgene bottle and placed in one arm of a v-mixer. Packing material was placed around the container to keep it from moving within the v-mixer. The soil was mixed for $2 \mathrm{hr}$ in an attempt to homogenize the DU throughout the soil.

Soil samples of $30 \mathrm{~g}$ each were constructed and placed into $250 \mathrm{ml}$ Nalgene bottles. The Nalgene bottles can be placed directly onto the HPGe 
detector's window to improve counting statistics. The relatively small volume of soil in the large container also allows the soil to take a large, wide, and thin geometry that covers a large portion of the detector window. This placement improves efficiency measurements by minimizing the variability in detector-source geometry. Gamma-ray attenuation through the soil for both low- and high-energy gamma rays is also reduced.

\subsubsection{Leaching procedures}

The overall procedures for this study are as follows:

1. $30 \mathrm{~g}$ of sieved DU-contaminated soil was placed into a $250 \mathrm{ml}$ Nalgene bottle.

2. The sample was placed on the HPGe detector, and a spectrum was collected for $24 \mathrm{hr}$.

3. $150 \mathrm{ml}$ of leaching solution was added to the Nalgene bottle containing the test soil.

4. The bottle was vigorously agitated to completely wet the soil within the bottle.

5. The bottle was cracked open approximately every 30 seconds to release any pressure from gasses formed inside the bottle. This process was repeated until no more gas was being generated.

6. The bottles were placed on a shaker table set to $250 \mathrm{rpm}$ and left to shake for the specified length of time and temperature defined by the test matrix in Table 17. The shaker table could also be used to control the temperature of the solutions (Figure 24).

7. The soil sample was removed from the shaker table and left to rest for $2 \mathrm{hr}$ to let particles in suspension settle.

8. The leaching solution was decanted. As much of the solution was removed as possible while leaving the solid material behind.

9. Another $100 \mathrm{ml}$ of leaching solution was added to the bottle containing the leached soil.

10. The soil and leaching solution were vigorously agitated for approximately 30 seconds.

11. The sample was left to rest for another $2 \mathrm{hr}$ to let particles in suspension settle.

12. The remaining liquid was decanted and combined with the originally decanted liquid. 
13. The sample soil sample was left in the bottle and placed with the lid off in an oven at $65.6^{\circ} \mathrm{C}$ for $48 \mathrm{hr}$ to dry.

14. The soil sample was placed back on the HPGe detector, and a postleaching spectrum was collected for $24 \mathrm{hr}$.

15. The spectra file was analyzed and the efficiency calculations made.

Figure 24. Shaker table used to agitate soil samples undergoing the leach procedure.

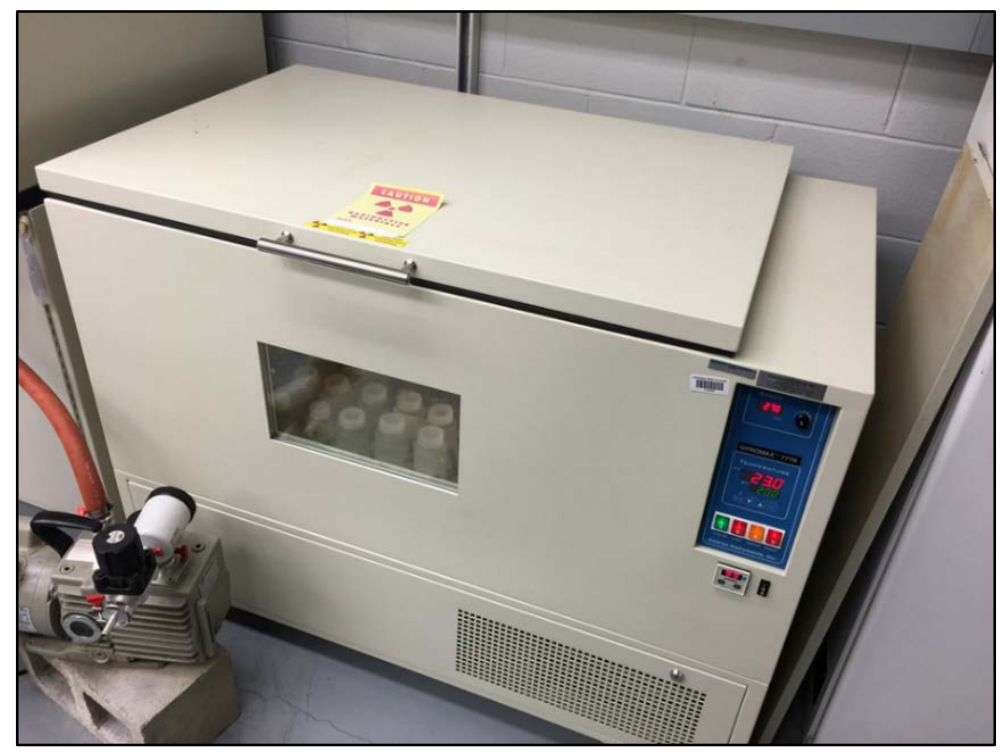

\subsection{Results and discussion}

\subsubsection{Leaching solution efficiencies}

Table 18 shows the results of the leaching solutions using the U-235 photopeak and compared to the U-238 (Pa-234m) photopeak. This data shows that the calculated efficiency using the Pa-234m photopeak (U-238) is much lower than that using U-235 and is less consistent.

As discussed earlier, disruption of the secular equilibrium of the U-238, Th-234, and Pa-234m decay series reduces the usefulness of using the $1001 \mathrm{keV}$ for measuring U-238. The results shown in Table 18 indicate that the leaching solutions have an impact on the equilibrium of Th-234 with U-238. It may be that the Th-234 forms Th oxides as the U decays. Literature states that Th oxides are only soluble in high-concentration nitric-acid solutions with fluoride ions present to act as a catalyst (Zimmer and Merz 1984; Chaudhury et al. 2006). For measuring the decay of Pa-234m to be practical, the leaching solutions must dissolve both $\mathrm{U}$ and Th equally to 
maintain the secular equilibriums. Because it is impractical to use the gamma ray emitted from $\mathrm{Pa}-234 \mathrm{~m}$ for $\mathrm{U}$ measurements, analysis must rely on the gamma emissions from U-235.

The results shown in Table 18 also indicate that a combination of AA and HAN solution leaches approximately $70 \%$ of the U. The leaching solution performed optimally at a 2 M concentration with $15 \%$ (v/v) 0.3 M HAN hydrochloride. The $3 \mathrm{M}$ acetic-acid solution works just as well, but the $2 \mathrm{M}$ solution could be used to reduce costs. Leaching is complete within $8 \mathrm{hr}$ at $21^{\circ} \mathrm{C}$.

Sulfuric and nitric-acid solutions outperformed any of the single aceticacid solutions. The best performer, with an efficiency above $90 \%$, was the soil sample pretreated with the $\mathrm{HCl}$ solution and then leached with the 3 M AA/ HAN solution. This combination also outperformed the single sulfuric and nitric-acid leaching solutions.

Table 18. Calculated leaching efficiencies using the U-235 photopeak for each leach test and the U-238 photopeak for comparison.

\begin{tabular}{|c|c|c|}
\hline Solution & $\begin{array}{c}\text { U-235 Efficiency } \\
\text { (\%) }\end{array}$ & $\begin{array}{c}\text { U-238 Efficiency } \\
\text { (\%) }\end{array}$ \\
\hline $1 \mathrm{M} \mathrm{AA}, 15 \% 0.3 \mathrm{M} \mathrm{HAN}$ & 62.03 & 33.34 \\
\hline $2 \mathrm{M} \mathrm{AA}, 15 \% 0.3 \mathrm{M} \mathrm{HAN}$ & 72.54 & 47.20 \\
\hline 3 M AA, 15\% 0.3 M HAN & 70.37 & 50.33 \\
\hline $3 \mathrm{M}$ AA, No HAN & 75.49 & 54.75 \\
\hline $3 \mathrm{M} \mathrm{AA}, \mathrm{H}_{2} \mathrm{O}_{2}$ & 36.70 & 32.05 \\
\hline $3 \mathrm{M} \mathrm{AA}, \mathrm{MnO}_{2}$ & 73.26 & 28.70 \\
\hline 3 M AA, 15\% 0.3 M HAN-8 hr Leach & 69.59 & 50.08 \\
\hline 3 M AA, 15\% 0.3 M HAN-16 hr Leach & 70.12 & 51.69 \\
\hline 3 M AA, 15\% 0.3 M HAN-24 hr Leach & 70.66 & 48.20 \\
\hline 3 M AA, 15\% 0.3 M HAN- 48 hr Leach & 71.80 & 53.70 \\
\hline 3 M AA, 15\% 0.3 M HAN-24 hr 3 M HCL Soak & 91.28 & 77.30 \\
\hline $3 \mathrm{M} \mathrm{AA}, 15 \% 0.3 \mathrm{M} \mathrm{HAN}-4^{\circ} \mathrm{C}-6$ days & 73.28 & 45.22 \\
\hline $3 \mathrm{M} \mathrm{AA}, 15 \% 0.3 \mathrm{M} \mathrm{HAN}-15.5^{\circ} \mathrm{C}-3$ days & 71.37 & 46.62 \\
\hline $0.3 \mathrm{M} \mathrm{C}_{6} \mathrm{H}_{8} \mathrm{O}_{7}$ & 66.95 & 67.16 \\
\hline $1 \mathrm{M} \mathrm{HNO}_{3}$ & 86.34 & 75.99 \\
\hline $1 \mathrm{M} \mathrm{H}_{2} \mathrm{SO}_{4}, 0.02 \% \mathrm{MnO}_{2}$ & 84.36 & 80.30 \\
\hline $0.1 \mathrm{M} \mathrm{NaHCO}_{3}, 15 \% \mathrm{H}_{2} \mathrm{O}_{2}$ & 34.19 & 16.21 \\
\hline $0.05 \mathrm{M} \mathrm{Na}_{2} \mathrm{CO}_{3} / 0.05 \mathrm{M} \mathrm{NaHCO}_{3}$ & 30.70 & 20.39 \\
\hline
\end{tabular}


The ratio of the Pa-234m to U-235 photopeak data was calculated before and after leaching (Table 19). Dissolution of $U$ is not dependent on the isotope. Therefore, the change in the U-235/ $\mathrm{Pa}-234 \mathrm{~m}$ ratio from pre- to postleach is most likely due to a reduced leachability of Th relative to $U$. The difference in photopeak ratios is most likely from the difference in leaching potential between $\mathrm{U}$ and $\mathrm{Th}$. With Th absorbing to the soil more effectively than U in many of the leaching systems, the U-238, Th-234, and Pa$234 \mathrm{~m}$ secular equilibrium has been altered; and, therefore, the intensity of the $1001 \mathrm{keV}$ Pa-234m photopeak is reduced. It is important to note that in approximately 224 days (ten times the Th-234 half-life), once Th-234 is back in secular equilibrium with U-238, the $1001 \mathrm{keV}$ photopeak could be used.

Table 19. Calculated photopeak ratios between U-235 and U-238 pre- and postleaching.

\begin{tabular}{|c|c|c|}
\hline \multirow[b]{2}{*}{ Solution } & \multicolumn{2}{|c|}{ Ratios } \\
\hline & $\begin{array}{c}\text { U-235/ } \\
\text { Pa-234m } \\
\text { Preleach }\end{array}$ & $\begin{array}{c}\text { U-235/ } \\
\text { Pa-234m } \\
\text { Postleach }\end{array}$ \\
\hline $1 \mathrm{M} \mathrm{AA}, 15 \% 0.3 \mathrm{M} \mathrm{HAN}$ & 3.73 & 2.12 \\
\hline $2 \mathrm{M} \mathrm{AA}, 15 \% 0.3 \mathrm{M} \mathrm{HAN}$ & 3.77 & 1.96 \\
\hline $3 \mathrm{M} \mathrm{AA}, 15 \% 0.3 \mathrm{M}$ HAN & 3.78 & 2.25 \\
\hline 3 M AA, No HAN & 3.77 & 2.04 \\
\hline $3 \mathrm{M} \mathrm{AA}, \mathrm{H}_{2} \mathrm{O}_{2}$ & 3.74 & 3.49 \\
\hline $3 \mathrm{M} A \mathrm{~A}, \mathrm{MnO}_{2}$ & 3.78 & 1.42 \\
\hline $3 \mathrm{M} \mathrm{AA}, 15 \% 0.3 \mathrm{M} \mathrm{HAN}-8 \mathrm{hr}$ & 3.80 & 2.31 \\
\hline $3 \mathrm{M} \mathrm{AA}, 15 \% 0.3 \mathrm{M} \mathrm{HAN}-16 \mathrm{hr}$ & 3.73 & 2.30 \\
\hline $3 \mathrm{M}$ AA, $15 \% 0.3 \mathrm{M} \mathrm{HAN}-24 \mathrm{hr}$ & 3.76 & 2.13 \\
\hline $3 \mathrm{M}$ AA, $15 \% 0.3 \mathrm{M}$ HAN-48 hr & 3.76 & 2.29 \\
\hline $3 \mathrm{M}$ AA, 15\% 0.3 M HAN-24 hr 3 M HCL Soak & 3.78 & 1.45 \\
\hline $3 \mathrm{M} \mathrm{AA}, 15 \% 0.3 \mathrm{M} \mathrm{HAN}-4.4^{\circ} \mathrm{C}$ & 3.81 & 1.86 \\
\hline $3 \mathrm{M} \mathrm{AA}, 15 \% 0.3 \mathrm{M} \mathrm{HAN}-15.6^{\circ} \mathrm{C}$ & 3.81 & 2.04 \\
\hline 0.3 M Citric Acid & 3.78 & 3.80 \\
\hline $1 \mathrm{M} \mathrm{HNO}_{3}$ & 3.70 & 2.10 \\
\hline $1 \mathrm{M} \mathrm{H}_{2} \mathrm{SO}_{4}, 0.02 \% \mathrm{MnO}_{2}$ & 3.72 & 2.95 \\
\hline $0.1 \mathrm{M} \mathrm{NaHCO}_{3}, 15 \% \mathrm{H}_{2} \mathrm{O}_{2}$ & 3.83 & 3.01 \\
\hline $0.05 \mathrm{M} \mathrm{Na}_{2} \mathrm{CO}_{3} / 0.05 \mathrm{M} \mathrm{NaHCO}_{3}$ & 3.74 & 3.25 \\
\hline
\end{tabular}

The DU soil sample that was presoaked in HCl performed significantly better than the standard acetic-acid solutions. Additional tests were conducted using $\mathrm{HCl}$ soaks. A second $\mathrm{HCl}$ soak and leaching was performed 
on selected soil samples that were previously tested. Soil samples tested with the $1 \mathrm{M}$ AA solution, $3 \mathrm{MAA}$ with $8 \mathrm{hr}$ leach, $\mathrm{HNO}_{3}$, and $\mathrm{H}_{2} \mathrm{SO}_{4} / \mathrm{MnO}_{2}$ were soaked with $100 \mathrm{ml}$ of $3 \mathrm{M} \mathrm{HCl}$ to see if additional $\mathrm{U}$ could be removed. Table 20 shows the results.

Table 20. Comparison of removal efficiency (\%) of uranium from DU-contaminated soil in a second set of leach tests using a $\mathbf{2 4} \mathrm{hr}$ hydrochloric-acid presoak and additional leaching with $3 \mathrm{M}$ acetic acid.

\begin{tabular}{|c|c|c|}
\hline \multirow[b]{2}{*}{ Sample and Leaching Procedure } & \multicolumn{2}{|c|}{$\begin{array}{l}\text { Removal efficiency } \\
\text { (\%) }\end{array}$} \\
\hline & First Leach & Second Leach \\
\hline $\begin{array}{l}24 \mathrm{hr} 3 \mathrm{M} \mathrm{HCl} \text { presoak, } \\
1 \mathrm{M} \mathrm{AA}, 15 \% \text { 0.3 M HAN leach, } \\
3 \mathrm{M} \mathrm{AA} \mathrm{leach}\end{array}$ & 62.03 & 85.65 \\
\hline $\begin{array}{l}24 \mathrm{hr} 3 \mathrm{M} \mathrm{HCl} \text { presoak, } \\
3 \mathrm{M} \mathrm{AA}, 15 \% \text { 0.3 M HAN with } 8 \mathrm{hr} \text { leach, } \\
3 \mathrm{M} \text { AA leach }\end{array}$ & 69.59 & 93.74 \\
\hline $\begin{array}{l}24 \mathrm{hr} 3 \mathrm{M} \mathrm{HCl} \text { presoak, } \\
1 \mathrm{M} \mathrm{HNO}_{3} \\
3 \mathrm{M} \mathrm{AA} \text { leach }\end{array}$ & 86.34 & 95.17 \\
\hline $\begin{array}{l}24 \mathrm{hr} 3 \mathrm{M} \mathrm{HCl} \text { presoak } \\
1 \mathrm{M} \mathrm{H}_{2} \mathrm{SO}_{4}, 0.02 \% \mathrm{MnO}_{2} \text {, leach } \\
3 \mathrm{M} \mathrm{AA} \mathrm{leach}\end{array}$ & 84.36 & 95.29 \\
\hline
\end{tabular}

An $\mathrm{HCl}$ soak improved the performance of the AA leach, an improvement evident in each leach test. As much as $90 \%$ of the $U$ can be removed from the soil column using $\mathrm{AA}$ and an $\mathrm{HCl}$ presoak during the leaching procedure. Additional $U$ is also leached from the soil samples previously leached with nitric acid and sulfuric acid. This indicates that it is possible that the $\mathrm{HCl}$ is increasing the $\mathrm{U}$ leachability by converting $\mathrm{U}$ oxides into more leachable chemical forms.

\subsubsection{Comparison to Naturally Occurring Radioactive Materials (NORM)}

Uncontaminated soil from the same vicinity as the DU-contaminated soil was retrieved, sieved, and analyzed with the HPGe detector at $185 \mathrm{keV}$ (U235). This soil sample was used as a comparative sample for the U content in "background" soil, or a measure of the naturally occurring radiation in the area. The total number of counts at the $185 \mathrm{keV}$ photopeak in the preand postleaching samples was compared to the uncontaminated soil sample (Figure 25). 
Figure 25. Ratio of U-235 in DU-contaminated soil samples to background, control soil samples before and after leaching.

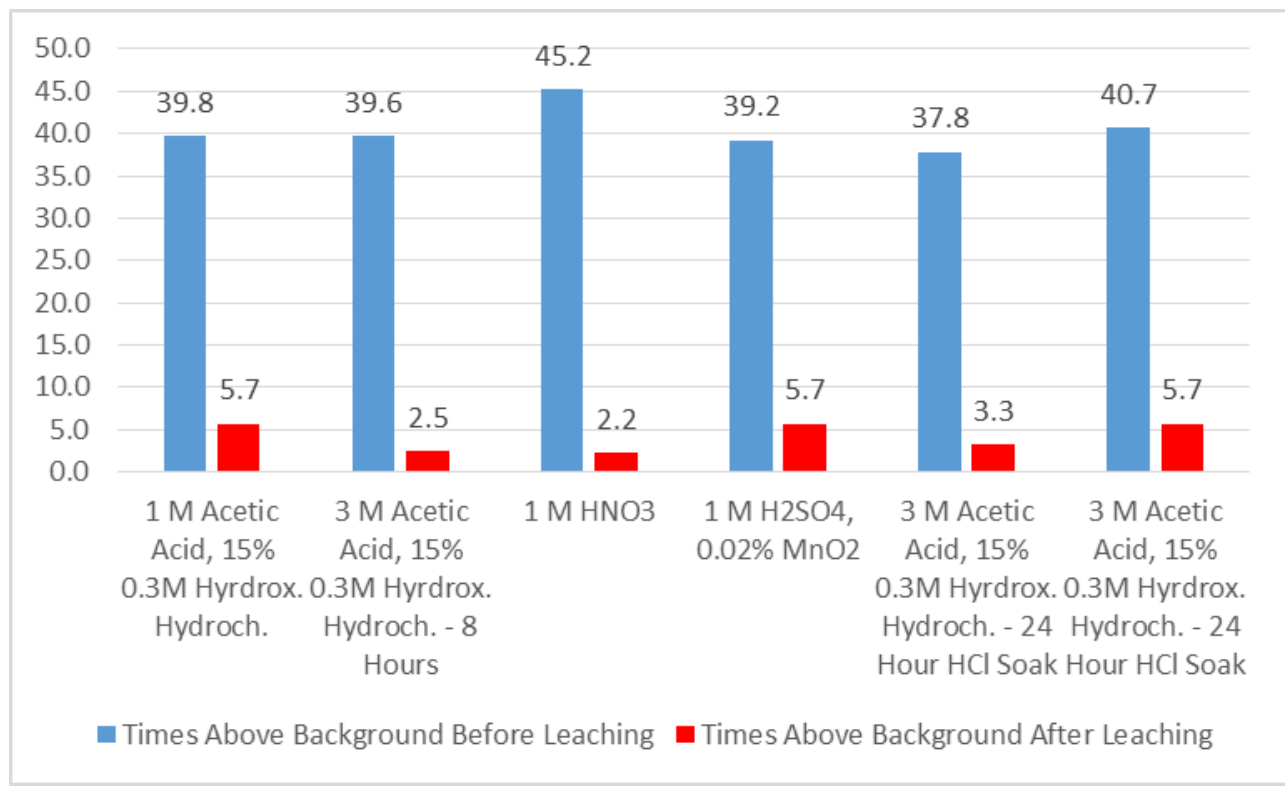

\subsection{Conclusions and recommendations}

The data presented here indicate that $\mathrm{AA}$ is functional at removing $\mathrm{U}$ from the DU-contaminated soils. Leaching efficiency without $\mathrm{HCl}$ presoaks is approximately $70 \%$. Leaching efficiency can potentially exceed $90 \%$ if the soil is pretreated with $3 \mathrm{M} \mathrm{HCl}$. Leaching is completed within $8 \mathrm{hr}$ at $21^{\circ} \mathrm{C}$. These leaching conditions are ideal for conducting large-scale heap leaching activities in the field. The generated leachate can be further processed to concentrate the $\mathrm{U}$ to reduce the costs of disposal. It is important to note that the leached soil samples still contain 2.2-5.7 times the amount of $U$ compared to an uncontaminated soil sample; however, it may be possible for leached soil to be reused on-site. If leached soil can be reused on-site, the cost of hazardous waste disposal will be significantly reduced. Cost modeling showed that the drivers were the soil volume to be remediated, the percentage of DU, and the area to be remediated. Comparing various treatment options, the model showed the lowest cost for remediation to be selective excavation of the contaminated soil followed by physical separation of that soil and chemical treatment of the residual soil fines (Farr et al. 2016; Walters et al. 2014). 


\section{Field-Ready Chemical Soll-Washing System}

\subsection{Objective}

The team designed a pilot-scale soil-leaching trailer system based on previous work conducted by MSU-ICET (McCown et al. 2015). The primary objective of the trailer system is to travel to field sites and to remediate onsite soils contaminated with DU.

Until now, the primary cost of remediating a site contaminated with DU has been transportation and disposal of the bulk radioactive soil. This research has demonstrated that the most cost-effective means of treating the DU in soil is a treatment train beginning with selective soil excavation, then physical separation of that soil, and followed by chemical treatment of the residual fines. The trailer system will allow soils to be chemically treated on-site, removing the additional cost of transporting and disposing of radioactive waste.

\subsection{System components}

Figure 26 presents a three-dimensional rendering of the trailer design.

Figure 26. 3D rendering of the leaching trailer.

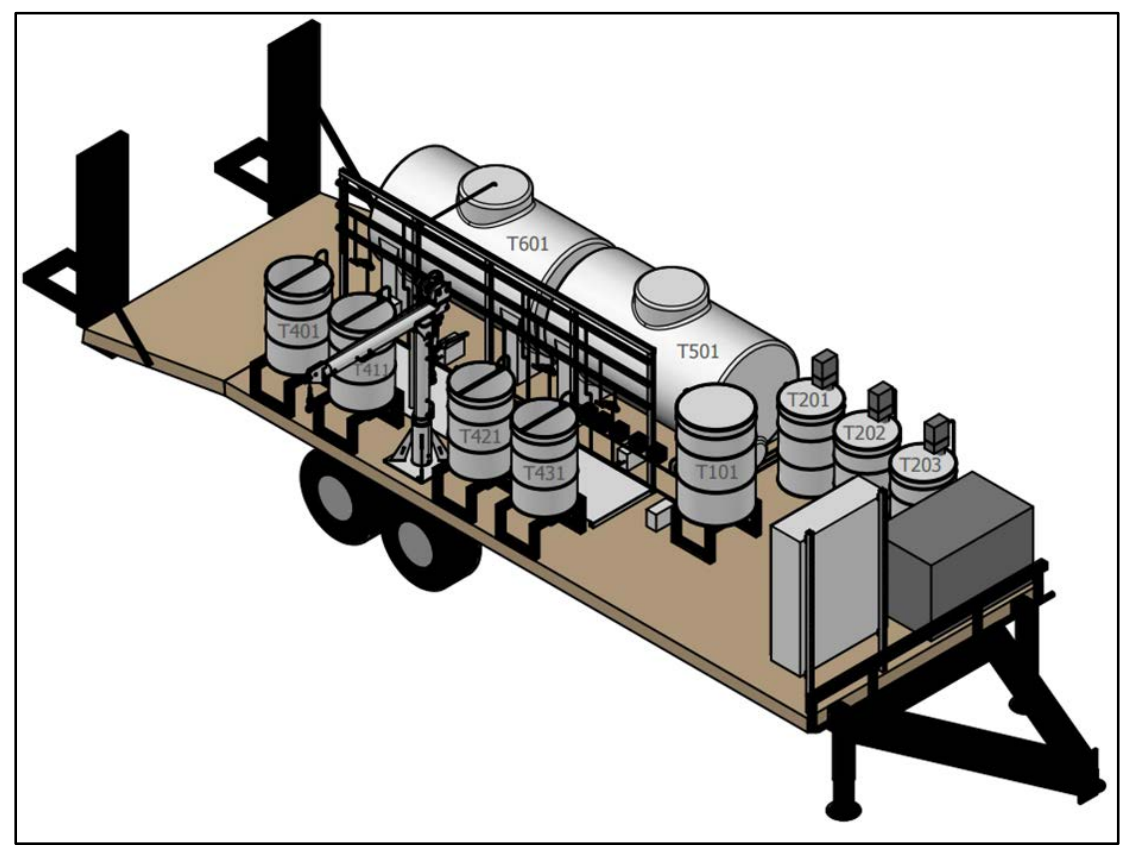


There are seven primary components to the trailer:

1. Supervisory control and data acquisition (SCADA) system

2. Leaching vessels (heaps), labeled T401, T411, T421, and T431

3. Pumps and plumbing

4. Solution mixing tank, labeled T101

5. Water/ wastewater storage, labeled T501 and T601

6. Concentrated Solution Tanks, labeled T201, T202, and T203

7. Sensors

\subsubsection{System control and data acquisition}

The SCADA will control all aspects of the leaching trailer. This includes mixing bulk leaching solutions, controlling valves and pumps, monitoring and adjusting chemistry composition during the leaching procedure, leachate waste transfer, and monitoring the $U$ concentration in the leachate by using a radiation detector system.

\subsubsection{Leaching vessels}

A total of four leaching vessels (heaps) are included in the design. The heaps are constructed of 55 gal. stainless steel drums. False bottoms on each heap act as a filtration system so the leaching solution can be recirculated from the bottom of the heap to the top. Spray nozzles will be placed on top of each heap to evenly distribute the leaching solution over the top of the heap. Each heap can contain approximately $0.99 \mathrm{~m}^{3}$ of soil, leaving enough room for the false bottom, filter media, and spray field.

The 55 gal. drums can be loaded and unloaded from the trailer, allowing the heaps to be filled and manipulated at ground level. Heaps can be loaded and unloaded onto the trailer for leaching, allowing for flexibility in the total number of vessels that can be used during the leaching procedure. Additionally, heaps can be loaded and prepared for leaching while other heaps are being leached or can be set aside so the heaps can be further processed or allowed to dry.

\subsubsection{Piping}

Stainless steel piping will be used to transfer fluids throughout the leaching system. Stainless steel piping is chosen due to its nonreactivity to AA 
and other chemical solutions. Lighter-weight materials like PVC could also be used that are safe to use with acetic-acid solutions below $10 \%$. However, PVC requires being joined by cements or glues, which can potentially react with aggressive chemicals and reduce the flexibility of the leaching system by limiting the number of usable solutions. Also, ultraviolet radiation can reduce impact strength of the exposed PVC. For long-term use, it would be better to choose a material like stainless steel as it avoids the issues associated with PVC.

\subsubsection{Pumps and valves}

Gear pumps will be used to transfer fluids around the system. The gear pumps can be controlled by variable frequency drives (VFDs). Flow rates using VFD-driven pumps are adjusted by modifying the frequency of the power driven to the pumps. The pumps will be controlled through the control system via a VFD controller. The hydraulic conductivity and flow rates throughout the system depend highly on the soil texture. The VFD-controlled pumps will be required to maintain a continuous cycle through the leaching heap.

All of the valves within the design of the leaching trailer are electrically controlled by the SCADA system. Electric three-way ball valves are used in strategic locations throughout the leaching system for controlling where fluids are transported.

\subsubsection{Primary bulk mixing tank}

All of the leaching solutions used on the trailer will be generated from concentrated chemicals. These chemicals are stored in tanks labeled T201, T202, and T203. The SCADA system controls peristaltic metering pumps to add specific amounts of concentrated chemicals to the bulk mixing tank. A pump is used to thoroughly mix the leaching solution in the bulk mixing tank.

\subsubsection{Water and waste storage tanks}

The largest vessels on the trailer will be reserved for storing clean water and wastewater. The clean-water tank will hold water for creating the leaching and treatment solutions. The waste storage tank will store used and contaminated leachate solutions. 


\subsubsection{Sensors}

The leaching system will use a wide range of sensors to monitor the leaching chemistry. Chemistry monitoring sensors include $\mathrm{pH}$, temperature, oxidation-reduction potential, and conductivity. A radiation monitoring system is included in the liquid loop of the system to monitor radiative material in solution. Flow, pressure, and differential pressure sensors are used to monitor flow rates and liquid height of the leach heaps.

\subsection{Field leaching process}

The heart of the leaching trailer design is the four leach heap vessels, which can act as multipurpose vessels during the leaching process. The heaps can be used for leaching $U$ from the soil column, rinsing leached soil, or chemically neutralizing leached soil. The vessels can also be filled with additional filter media and be used to treat the waste leachate by extracting the dissolved U.

The trailer can be configured to work with contaminated soils in different stages:

- Pretreatment (HCl presoak) stage

- Leaching stage

- Rinsing stage

- Chemical neutralization stage

- Uranium concentration stage

The pretreatment, leaching, rinsing, and neutralization stages do not physically alter the configuration of the leach heaps. Each of these stages can be monitored and controlled by the SCADA as each stage is chemically different and can be changed by the addition or complete change of chemical solutions. Empty leach heaps could be filled with filter media to filter the U from the leaching solutions and to hold the clean leachate in the neutralization and concentration stages.

A minimum of four heaps is required during the leaching process. The number of heaps can be increased as needed. The initial step in the leaching procedure is to add soil to the leach heaps. The heaps can be filled by hand using a shovel or mechanically using a small backhoe. The heaps are lifted onto the trailer using the crane once filled approximately halfway. 
Figure 27 shows a piping and instrumentation diagram (P\&ID) of the bulk mixing tank, including concentrated solution tanks, pumps, and sensors. The blue arrows indicate the loop used for mixing bulk leaching solution. Figure 28 presents a P\&ID of the primary loops for transferring leachant, leachate, and waste. The red arrows in both figures indicate the loops used during the leaching process.

Water is transferred to the batch tank (T101) used to mix the leachant solution. The leaching solution is circulated from the bottom of the tank to the top during the mixing process to ensure thorough mixing. Concentrated chemicals (T201, T202, and T203) are added to the leaching solution until the desired concentrations and chemical parameters (including $\mathrm{pH}$ and oxidation-reduction potential) are achieved. The leaching solution is passed from valve V101 to valve 102 and sent to the leachant line of the leaching system. Leachant flows from the primary leachant line through each of the valves used to control the spray field into each of the four heaps: T401, T411, T421, T431 (Figure 28).

Leachate travels through the four heaps and is collected at the bottom of each heap. A pump connected to the bottom of each heap is used to transfer the waste leachate to the leachate line. The leachate line is connected back to the bulk-solution mixing tank (T101) where it can be chemically modified based on sensor readings. The chemically modified leachant is then transferred back to the leachant line where the solution is used again for leaching. Once leaching has been completed, the waste leachate is drained and transferred to the waste treatment tank (T601) through the waste line.

The primary purpose of this looping configuration is to provide leachant with the correct composition to the spray field of each heap and then to transfer leachant back to the batch mixing tank so it can be reused. The leachant should be reused as long as $U$ is being removed from the soil columns. The amount of $U$ leached is monitored using lanthanum bromide scintillation detectors located in the leachant and leachate lines loops of the system. 
Figure 27. P\&ID diagram of batch mixing tanks, pumps, and sensors. Red arrows indicate the heap recirculation loop; blue arrows indicate the mixing loop.

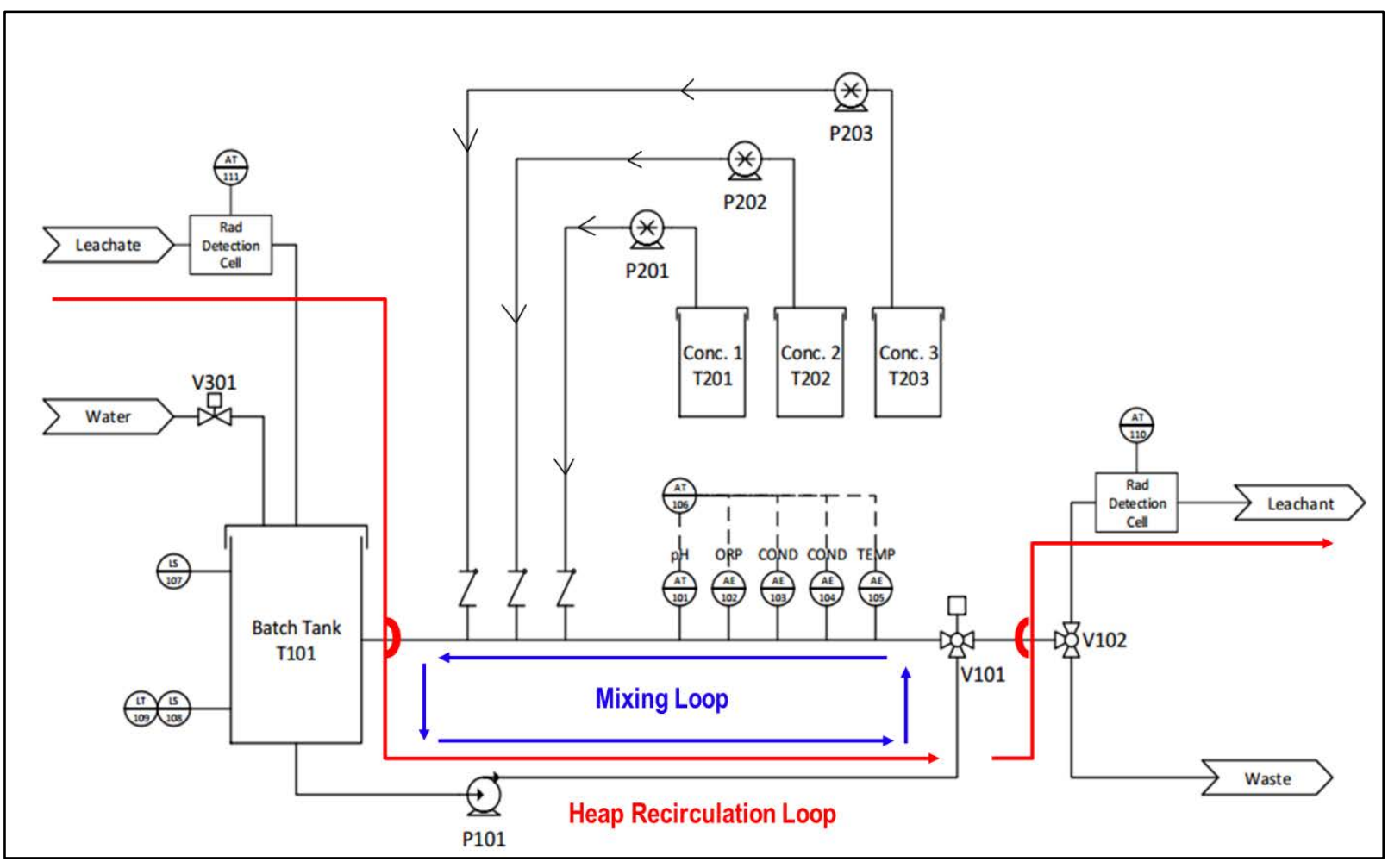


Figure 28. P\&ID diagram of liquid transfer lines and leaching loops for the leaching system. Red arrows indicate the heap recirculation loop.

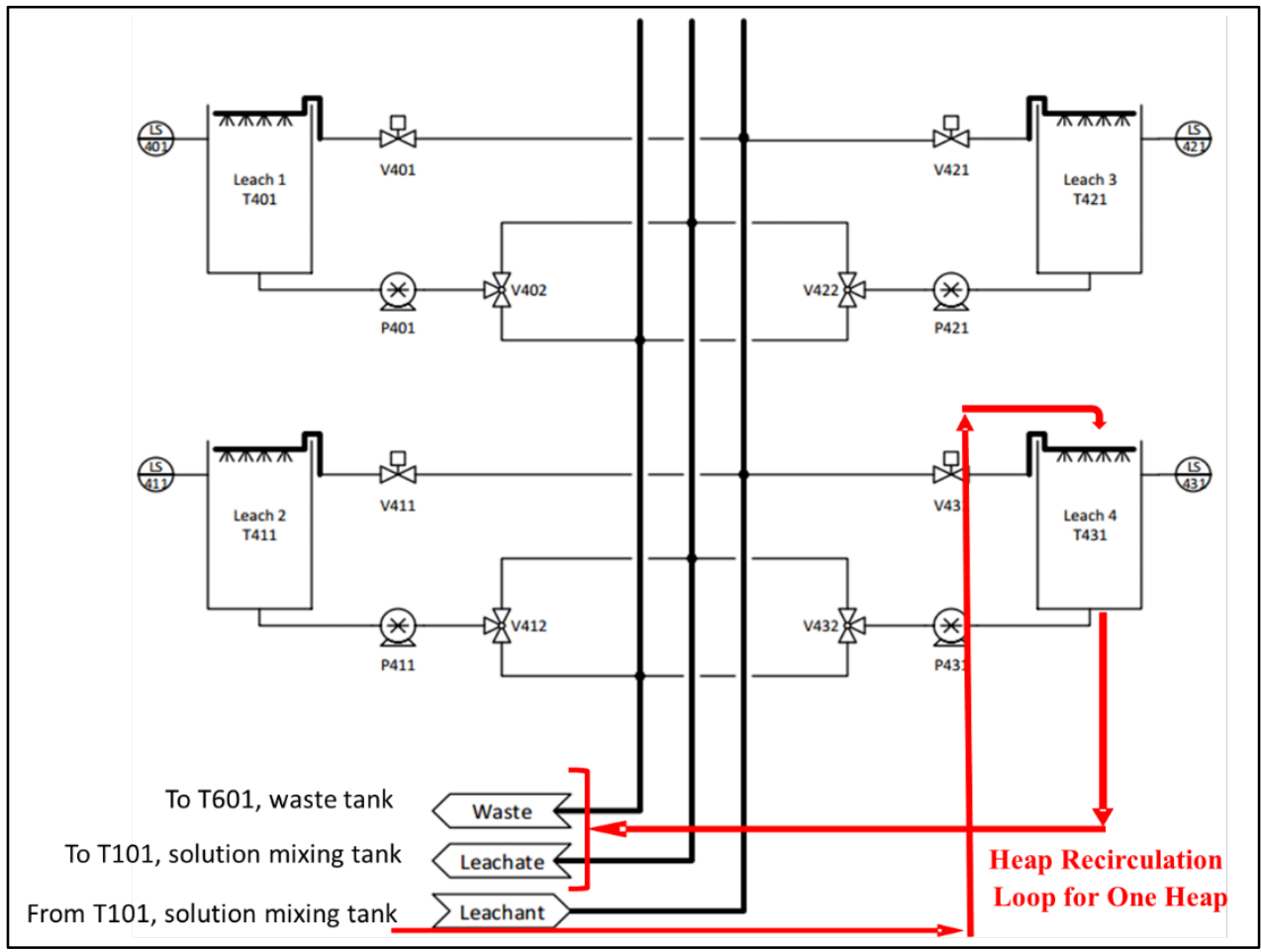

Each individual heap can also be removed from the leaching loop. This allows for continual removal and introduction of unleached soil without having to waste leachate that could potentially be usable.

All of the leachate is drained from the system if it is found to no longer be effective at removing $U$. This will be determined using the radiation detector system discussed in the bench-scale systems sections (Sections 2 and 3 in this report). Additional leaching solution can be created as needed. A new solution is created to chemically neutralize the $\mathrm{pH}$ of the soil after the leaching procedure is complete. This process ensures that the soil is environmentally safe before being reintroduced back into the environment. 


\section{Conclusions}

The bench-scale leach system was used to quantify the performance of the AA/ HAN leaching solutions. Sieved DU-contaminated soil was used with the bench-scale leach system to determine how well the AA/HAN leaching solutions would work with field-contaminated soil. The study analyzed the soil samples before and after the leaching procedures. The optimum leaching solution was found to be $2 \mathrm{MAA}$ with a $15 \%$ (v/v) of $0.3 \mathrm{M} \mathrm{HAN}$. Results also showed that leaching was complete within $8 \mathrm{hr}$ at $21^{\circ} \mathrm{C}$ with an average leaching efficiency of around $62 \%-69 \%$. An $\mathrm{HCl}$ presoak on soil samples followed by the optimal $2 \mathrm{MAA} / \mathrm{HAN}$ leach was the most effective leaching procedure, which boosted leaching efficiency to 85\%-91\%. The leaching efficiencies achieved with higher concentrations of AA ( 2 or $3 \mathrm{M}$ ), longer leach times, or higher leaching temperatures were all similar. Reduction of DU contamination of the soils results in reduced quantities of radioactive material that require long-term storage and transportation to a long-term storage site. This also reduces the risk of radioactive exposure to installation personnel.

The team designed a mobile system for leaching DU from soil and fit it to a trailer able to go to the field. The mobile system incorporates four heap leaching vessels, clean and wastewater storage, solution mixing tanks, and storage tanks for concentrated solutions. Sensors on the trailer track through a SCADA system the progress of the soil leaching. The trailer can be configured to work with contaminated soils in several different stages of the heap leaching process: $\mathrm{HCl}$ presoak, soil leaching and rinsing, chemical neutralization, or U concentration stages. By doing so, the trailer reduces transportation costs and safety concerns associated with transport of radioactive materials off-site for treatment.

Overall, this leaching procedure, in conjunction with the mobile leaching system, will reduce the remediation cost of DU-contaminated soils under stewardship of the U.S. Army. 


\section{References}

AEPI (Army Environmental Policy Institute). 1994. Health and Environmental Consequences of Depleted Uranium Use by the U.S. Army. Summary Report to Congress. Atlanta, CA: Army Environmental Policy Institute.

BatesIsBack. 2011. Decay Chain of Thorium. CC-BY-SA-3.0. Wikimedia Commons. https://commons.wikimedia.org/wiki/File:Decay_Chain_of_Thorium.svg (accessed August 2017).

Betti, M. 2003. Civil Use of Depleted Uranium. J ournal of Environmental Radioactivity 64:113- 119.

Bleise, A., P. R. Danesi, and W. Burkart. 2003. Properties, Use and Health Effects of Depleted Uranium (DU): A General Overview. J ournal of Environmental Radioactivity 64:93- 112.

Buck, B. J., A. L. Brock, W. H. J ohnson, and A. L. Ulery. 2004. Corrosion of Depleted Uranium in an Arid Environment: Soil-Geomorphology, SEM/ EDS, XRD, and Electron Microprobe Analyses. Soil and Sediment Contamination 13:545- 561.

Chaudhury, S., M. Keskar, A. Patil, K. Singh Mudher, and V. Venugopal. 2006. Studies on the Dissolution Behavior of $\mathrm{ThO}_{2}$ and $(\mathrm{U}, \mathrm{Th}) \mathrm{O}_{2}$ by a Solid State Reaction Method. Radiochimica Acta 94(6- 7): 357- 361.

Choy, C., G. Korfiatis, and X Meng. 2006. Removal of Depleted Uranium from Contaminated Soils. J ournal of Hazardous Materials 136:53-60.

Crean, D., F. Livens, M. Sajih, M. Stennett, D. Grolimund, C. Borca, and N. Hyatt. 2013. Remediation of Soils Contaminated with Particulate Depleted Uranium by Multi Stage Extraction, J ournal of Hazardous Materials 263(2): 382- 290.

Duff, M., C. Mason, and D. Hunter. 1998. Comparison of Acid and Base Leach for the Removal of Uranium from Contaminated Soil and Catch-Box Media. Canadian J ournal of Science 28(4): 675-683.

Edwards, C., and A. Oliver. 2000. Uranium Processing: A Review of Current Methods and Technology. J ournal of the Mineral, Metals, and Materials Society 52:12- 20.

Farr, J . V., I. J . Faber, A. Ganguly, W. A. Martin, and S. L. Larson. 2016. SimulationBased Costing for Early Phase Life Cycle Cost Analysis: Example Application to an Environmental Remediation Project. The Engineering Economist 61: 207222. doi:10.1080/0013791X.2015.1062582.

Frackiewicz, K., K. Kiegiel, I. Herdzik-Koniecko, E. Chajduk, G. Zakrzewska-Trznadel, S. Wolkowicz, J . Chwastowska, and I. Bartosiewicz. 2012. Extraction of Uranium from Low-Grade Polish Ores: Dicytonemic Shales and Sandstones. NUKLEONIKA 58:451- 459.

Francis, A., and C. Dodge. 1998. Remediation of Soils and Wastes Contaminated with Uranium and Toxic Metals. Environmental Science Technology 32:3993- 3998. 
Gilmore, G. 2008. Practical Gamma Ray Spectrometry. 2nd ed. West Sussex, UK: J ohn Wiley \& Sons Ltd.

Guettaf, H., A. Becis, K. Ferhat, K. Hanou, D. Bouchiha, K. Yakoubi, and F. Ferrad. 2009. Concentration-Purification of Uranium from an Acid Leaching Solution. Physics Procedia 2:765- 771.

International Atomic Energy Agency. 1993. Uranium Extraction Technology. Technical Report Series No. 359. Vienna, Austria: International Atomic Energy Agency.

Knoll, G. 2000. Radiation Detection and Measurement. 3rd ed. Hoboken, NJ : J ohn Wiley \& Sons, Inc.

L'Annunziata, M. 2003. Handbook of Radioactivity Analysis. 2nd ed. San Diego, CA: Academic Press and Imprint of Elsevier.

Larson, S., B. Ballard, V. Medina, M. Thompson, G. O'Connor, C. Griggs, and C. Nestler. 2009. Separation of Depleted Uranium from Soil. ERDC/ EL TR-09-1. Vicksburg, MS: U.S. Army Engineer Research and Development Center.

Larson, S., V. Medina, J . Ballard, C. Griggs, M. Wynter, D. Mackie, B. King, and C. Nestler. 2012. Large-Scale Physical Separation of Depleted Uranium from Soil. ERDC/ EL TR-12-25. Vicksburg, MS: U.S. Army Engineer Research and Development Center.

Mason, C., W. Turney, M. Thomson, N. Lu, P. Longmire, and C. Chisholm-Brause. 1997. Carbonate Leaching of Uranium from Contaminated Soils. Environmental Science Technology 31:2701-2711.

McCown, J ., R. Unz., C. Waggoner, J . Ballard, S. Larson, and P. Arienti. 2015. Development of Scalable Process Control System for Chemical Washing to Remove Uranyl Oxide. ERDC/ EL TR-15-4. Vicksburg, MS: U.S. Army Engineer Research and Development Center.

Mellini, M., and F. Riccobono. 2005. Chemical and Mineralogical Transformations Caused by Weathering in Anti-Tank DU Penetrators ("The Silver Bullets") Discharged during the Kosovo War. Chemosphere 60:1246- 1252.

Nichols, A., D. Aldama, and M. Verpelli. 2008. Handbook of Nuclear Data for Safeguards: Database Extensions. Vienna, Austria: International Atomic Energy Agency, International Nuclear Data Committee.

Nuclear Regulatory Commission. 2015. Part 110 Export and Import of Nuclear Equipment and Equipment, Subpart 110.2 Definitions. In Title 10, Code of Federal Regulations. Last updated 2 December 2015. https://www.nrc.gov/reading$\mathrm{rm} /$ doc-collections/cfr/part110/index.html.

Phillips, E. J . P., E. R. Landa, and D. R. Lovley. 1995. Remediation of Uranium Contaminated Soils with Bicarbonate Extraction and Microbial U(VI) Reduction. J ournal of Industrial Microbiology 14:203-207.

Prado, F. 2012.M1A1/ 2 Abrams. The Armor Site. http://www.fprado.com/armorsite/abrams.htm (accessed J une 2017). 
Richter, S., A. Alonso, W. De Bolle, R. Wellum, and P. D. P. Taylor. 1999. Isotopic "Fingerprints" for Natural Uranium Ore Samples. International J ournal of Mass Spectroscopy 193:9- 14.

Salbu, B., K. J anssens, O. Lind, K. Proost, and P. Danesi. 2003. Oxidation States of Uranium in DU Particles from Kosovo. J ournal of Environmental Radioactivity 64:167- 173.

Seidel, D. 1981. Extraction of Uranium from its Ores. IAEA Bulletin 23:65- 73.

Toque, C., A. E. Milodowski, and A. C. Baker. 2014. The Corrosion of Depleted Uranium in Terrestrial and Marine Environments. J ournal of Environmental Radioactivity 128:97- 105.

Unz, R., D. Rogers, C. J ones, J . McCown, and C. Waggoner. 2011. Use of Lanthanum Bromide Detectors to Augment Site Surveys for Depleted Uranium. In Proceedings of the ASME 14th International Conference on Environmental Remediation and Radioactive Waste Management, 25- 29 September, Reims, France, 823- 830. American Society of Mechanical Engineers. doi:10.1115/ ICEM2011-59169.

U.S. EPA (United States Environmental Protection Agency). 2006. Depleted Uranium. Technical Brief. EPA-402-R-06-011, Office of Air and Radiation, Washington, DC.

U.S. Geological Survey. N.d. The Uranium-238 Decay Chain. Reston, VA: U.S. Geological Survey. https://pubs.usgs.gov/of/2004/1050/PalosVerdesRn.htm\#uranium.htm.

Vaughn, C., R. Unz, D. Rogers, J . McCown, C. Jones, and C. Waggoner. 2011. A. Sodium Iodide and Lanthanum Bromide Detector Equipped Gamm Survey System for Enhancing Discrimination between Contamination and Naturally Occurring Radiological Material. Proceedings of the WM Symposia 2011 Conference, 27 February- 3 March, Phoenix, AZ.

Walters, J ., J . Mackey, K. Maki, R. Northcutt, J . Farr, A. Martin, S. Larson, J . Ballard, and C. Nestler. 2014. Cost Analysis of Remediation Systems for Depleted Uranium. ERDC/ EL TR-14-5. Vicksburg, MS: U.S. Army Engineer Research and Development Center.

Yücel, H., M. Çetiner, and H. Demirel. 1998. Use of the 1001 keV Peak of 234mPa Daughter of $238 \mathrm{U}$ in Measurement of Uranium Concentration by HPGe Gamma-Ray Spectrometery. Nuclear Instruments and Methods in Physics Research 413:7482.

Zimmer, E., and E. Merz. 1984. Dissolution of Thorium-Uranium Mixed Oxides in Concentrated Nitric Acid. J ournal of Nuclear Materials 124:64- 67. 


\section{REPORT DOCUMENTATION PAGE}

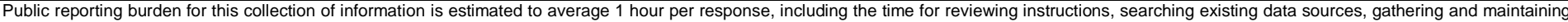

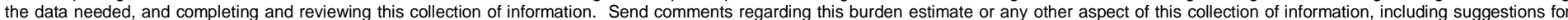

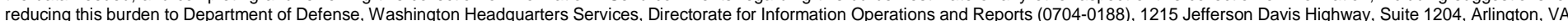

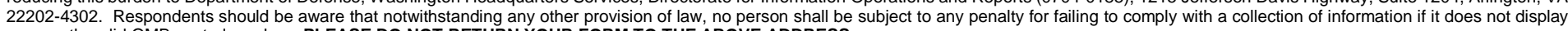
a currently valid OMB control number. PLEASE DO NOT RETURN YOUR FORM TO THE ABOVE ADDRESS.
1. REPORT DATE (DD-MM-YYYY)
2. REPORT TYPE
January 2018
Technical Report/Final

\section{TITLE AND SUBTITLE}

Development and Characterization of Small-Scale Washing Systems for Removal of

Depleted Uranium Oxides

3. DATES COVERED (From - To)

5a. CONTRACT NUMBER

5b. GRANT NUMBER

5c. PROGRAM ELEMENT NUMBER

0603728A

\section{AUTHOR(S)}

5d. PROJECT NUMBER

Ronald J. Unz, Jay P. McCown, Charles A. Waggoner,

Steven L. Larson, and John H. Ballard

5e. TASK NUMBER

5f. WORK UNIT NUMBER

\section{PERFORMING ORGANIZATION NAME(S) AND ADDRESS(ES)}

8. PERFORMING ORGANIZATION REPORT NUMBER

Environmental Laboratory

U.S. Army Engineer Research and Development Center

ERDC/EL TR-18-1

3909 Halls Ferry Rd.

Vicksburg, MS 39180

9. SPONSORING I MONITORING AGENCY NAME(S) AND ADDRESS(ES)

10. SPONSOR/MONITOR'S ACRONYM(S)

USACE

Headquarters, U.S. Army Corps of Engineers

Washington, DC 20314-1000

11. SPONSOR/MONITOR'S REPORT NUMBER(S)

\section{DISTRIBUTION / AVAILABILITY STATEMENT}

Approved for public release; distribution is unlimited.

\section{SUPPLEMENTARY NOTES}

Environmental Quality/Installations (EQ/I)

\section{ABSTRACT}

Researchers from the Mississippi State University Institute for Clean Energy Technology (MSU-ICET) and the U.S. Army Engineer Research and Development Center (ERDC) have identified procedures and methodologies for identifying leaching solutions to assist in the removal of depleted uranium (DU) oxides from contaminated soils. They developed a bench-scale leach system to optimize leaching procedures and methodologies. This study identified that a 2 molar (M) acetic-acid solution with a $15 \%(\mathrm{v} / \mathrm{v}) 0.3 \mathrm{M}$ hydroxylamine hydrochloride solution could remove approximately $70 \%$ of the uranium in the soil sample. Pretreating the soil with $3 \mathrm{M}$ hydrochloric acid improved leaching efficiency to approximately $90 \%$. The MSU-ICET research team developed the preliminary design of a mobile leaching system based on the hydrochloric-acid pretreatment followed by $2 \mathrm{M}$ acetic acid / 15\% (v/v) $0.3 \mathrm{M}$ hydroxylamine hydrochloride leaching method. The trailer heap leach system is designed to be used on-site, eliminating the need for additional transport of radioactive, contaminated soils. This will reduce the risk of radioactive exposure for personnel and will eliminate potentially serious transportation accidents.

\section{SUBJECT TERMS}

Bench-scale washing system, Depleted uranium, Field leaching system, Hazardous waste site remediation, Hydroxylamine hydrochloride, Soil leaching, Soil pollution, Soil remediation

16. SECURITY CLASSIFICATION OF:

\section{a. REPORT}

Unclassified

\section{b. ABSTRACT}

Unclassified

\section{c. THIS PAGE}

Unclassified
17. LIMITATION OF ABSTRACT

SAR
18. NUMBER OF PAGES

69 19a. NAME OF RESPONSIBLE PERSON

19b. TELEPHONE NUMBER (include area code) 